\title{
Toward more comprehensive environmental impact assessments: interlinked global models of LCIA and IAM applicable to this century
}

\author{
Koji Tokimatsu ${ }^{1,2} \cdot$ Longlong Tang $^{3} \cdot$ Rieko Yasuoka $^{4} \cdot$ Ryota $^{5}{ }^{5} \cdot$ Norihiro Itsubo $^{6} \cdot$ Masahiro Nishio $^{2}$
}

Received: 15 November 2019 / Accepted: 9 March 2020 / Published online: 21 July 2020

(C) The Author(s) 2020

\begin{abstract}
Purpose Despite the long-standing demand for research on dynamic lifecycle assessment (LCA) for policymaking, only a few studies have addressed this subject in conjunction with other systems thinking disciplines, such as energy systems models (ESMs) and integrated assessment models (IAMs), which have achieved tremendous success in assessing climate policies in future scenarios. This study explains our methodological advances in the global application of LCA incorporated in IAMs, specifically dose-response functions, models, and future scenarios.

Methods We investigate the application of the lifecycle impact assessment method based on endpoint modeling (LIME), developed under the current environmental situation in Japan and globally, to be consistent and compatible with our IAM, which comprises three resource balance models and a simplified climate model. The IAM endogenously generates most inventories consistent with energy scenarios and climate policies linked with the applied LIME. The IAM and LIME are formulated to minimize the discounted sum of supplying the cost of resources over their lifecycles (i.e., from development to end-of-life) to generate time evolutions for the endpoint impacts over this century on a global scale with/without the 2-degree Celsius (2DC) target in a $100 \%$ renewable energy scenario.

Results and discussion Unlike existing LCA+ESM/IAM studies, which focus on power generation technologies and related (in)direct embedded energy consumption on a lifecycle basis, our model's expansion to mineral and biomass resources, in addition to energy, has the following novel results: (1) The following inventories in the 2DC target are generally lower than those in business as usual (BAU): temperature and sea level rise, natural resource, and waste discharge; further, SOx emissions are significantly reduced by reducing coal production while increasing forestry. (2) The environmental impacts on the four endpoints of minerals, land use, and land-use change, with the exclusion of energy-related impacts, are significantly larger than those related to energy. (3) Finally, by ensuring inventory reduction, the 2DC target scenario can reduce overall endpoint impacts (by maximum around 20\%), except the impacts on biodiversity resulting from forestry expansion to meet predetermined targets.

Conclusions Unlike mainstream IAM analyses, we incorporate LIME, instead of energy- and biomass-related resource and climate change impacts alone; our model thus provides a comprehensive perspective on various natural resources and their impacts on a lifecycle basis. The exclusion of the weighting process and retention of the four endpoints enable us to easily interpret the results. Further, this application of LCA to IAM enables us to further understand and assess natural resources and environmental impacts.
\end{abstract}

Keywords Lifecycle impactassessment (LCIA) · Integrated assessment model(IAM) · Endpoint impacts · Dose-response function (DRF) $\cdot$ Lifecycle impact assessment method based on endpoint modeling (LIME)

Responsible editor: Masaharu Motoshita

Koji Tokimatsu

tokimatsu.k.ac@m.titech.ac.jp

1 Tokyo Institute of Technology, 4259 Nagatsuta, Midori-ku, Yokohama, Kanagawa 226-8503, Japan

2 National Institute of Advanced Industrial Science and Technology, 1-2-1, Namiki, Tsukuba, Ibaraki 305-8564, Japan
3 Institute for Agro-Environmental Sciences, National Agriculture and Food Research Organization, 3-1-3 Kannondai,

Tsukuba, Ibaraki 305-8604, Japan

4 System Research Center Co., Ltd., KY Bldg., 3-16-7, Toranomon, Minato-ku, Tokyo 105-0001, Japan

5 Pacific Consultants Co., Ltd., 3-22 Kanda-Nishikicho, Chiyoda-ku, Tokyo 101-8462, Japan

6 Tokyo City University, 3-3-1 Ushikubo-nishi, Tsuzuki-ku, Yokohama, Kanagawa 224-8551, Japan 


\section{Introduction}

\subsection{Background: explorative lifecycle assessment}

Today, humankind faces new challenges in environmental externalities, as well as growth and scarcity (Simpson et al. 2005). Decade-long efforts have finally succeeded in globally mainstreaming climate change policy, with the initiation of the Intergovernmental Panel on Climate Change (IPCC), the International Resource Panel (IRP) for natural resources, and The Economics of Ecosystems and Biodiversity (TEEB) for biodiversity. However, newer issues are emerging, such as the disposal of plastic bags into the world's oceans. More comprehensive and holistic approaches are in demand since the environmental externalities have some common underlying economic activities, such as resource development, resource use, and consequential impacts.

Specific subjects have evolved new tools to tackle these issues. Systems thinking tools, energy systems models (ESMs) and/or integrated assessment models (IAMs), and lifecycle assessment (LCA) are commonly used to assess technology and the economy. They are complementary as well, in that the ESM/IAM performs dynamic (time evolution) in scenario analysis; however, it disregards indirect greenhouse gas (GHG) emissions on the bases of lifecycle. Therefore, LCA is better suited to assess the environment and geography. In addition, GHG accounting incorporates environmental impact assessment, whereas time evolutions or scenarios receive only basic static analysis and limited research effort.

Apart from some pioneering studies, these two tools have developed in parallel with a few interactions historically (e.g., Tokimatsu and Kaya 2004; Klaassen and Riahi 2007; Kosugi et al. 2009). However, several recent studies have examined this subject (Hertwich et al. 2015; García-Gusano et al. 2017a, b; Patrizio et al. 2017; Paulink et al. 2017; Arvesen et al. 2018; Boubault et al. 2018; Pehl et al. 2018; Volkart et al. 2018; Weidema et al. 2018; Tokimatsu et al. 2019). Bridging the methodological gap requires increasing the number of such studies on the operating models of LCA and ESM/IAM.

In "Digesting the alphabet soup of LCA," Guinée et al. (2018) label the LCA studies that explore scenarios of potential futures as "eXplorative LCA," or XLCA. Our study falls under this recently named category. Our work contains multiple "X" scenarios. "Backcasting LCA" explores how normatively defined sustainability levels (e.g., planetary boundaries) can be met. We also explore 2-degree Celsius (2DC) targets under the $100 \%$ renewable energy scenario (Ren100), called "scenario-based LCA." We do this by combining our lifecycle impact assessment (LCIA) model-the lifecycle impact assessment method based on endpoint modeling (LIME) - with our three resource balance models (one of which is a bottomup type energy systems model (ESM)) and a simplified climate model, categorized as "integrated" LCA. Since our IAM is a forward-looking, nonpredictive, and perfect foresight model, our work involves an aspect of "anticipatory LCA." Finally, we illustrate the damages at the four endpoints defined in our LIME over the time horizon to the year 2100 through our IAM, which corresponds to "prospective LCA." With this definition of eXplorative LCA, this study undertakes a modeling exercise to interlink the LCIA and ESM/IAM. Here, the words "interlinked" and "integrated" are used interchangeably and distinguished imprecisely. In general, interlinked seems to satisfy situations before the completion of integration or to separate one model from the other, whereas integrated is used after the integration of the models.

Thanks to Guinée et al. (2018), we refrain from dwelling on the varieties of LCA modes and, thereby, avoid muddled definition-related discussions. However, our further discussions focus on the integrated LCA mode, integrated LCIA models and systems (e.g., energy scenarios), and the scenario-based LCA mode.

\subsection{Literature review: integrating lifecycle assessment models and the Energy System Models and Integrated Assessment Models}

Vanderpaer and Gibon (2018) summarize prospective LCA from five attempts presented at a conference on the integration of energy scenarios into the LCA. They examine the challenges encountered in efforts to combine the two model domains (i.e., LCA and ESM/IAM) in terms of organizational, structural, technological, and methodological inconsistencies. Further, the authors present the perspectives of LCA practitioners on enabling data sharing, open sourcing, and best practices; however, due to their complexity and resource-intensive nature, they omit some perspectives. The current study includes these omitted perspectives as well.

There are three patterns of integration of LCA models and ESM/IAM:

First, a process-based "cradle to grave" approach using LCA data (e.g., Tokimatsu and Kaya 2004; Hertwich et al. 2015; García-Gusano et al. 2017a, b; Volkart et al. 2018), which is the soft-linkage of these models in some instances.

Second, multiplying the damage or economic factors (also called coefficient in other studies) in the LCIA database with inventories that are endogenously generated from the models through fully integrated, sometimes hard-linked, models (e.g., Pehl et al. 2018; Arvesen et al. 2018; Boubault et al. 2018; Tokimatsu et al. 2019). The third is a hybrid of the aforementioned and other categories.

The first approach, requiring process-based cradle-to-grave work, applies processes based on detailed inventory data for 
"input to and output from" the processes. These are either retrieved from LCA databases (Hertwich et al. 2015; GarcíaGusano et al. 2017a, b; Volkart et al. 2018) or are background data (Tokimatsu and Kaya 2004), for all the processes and stages following the blending of the database and model, along with the lifecycle of electricity generation (resource extraction, transport, distribution, process, construction, operation, decommission, and disposal).

García-Gusano et al. (2017a) examine the Spanish power sector through the Integrated MARKAL-EFOM System (TIMES), Spain's inventories and mid- and end-points, using the ReCiPe 2018 LCA database. They further explore modeling exercises integrating the LCA and the ESMs to show indicators over time, ranging from technology-based, environmental externalities, and energy security (García-Gusano et al., 2016, 2017b, 2018a, b).

Unlike these studies that run ESMs themselves, Hertwich et al. (2015) borrow power-mix scenarios from other studies to soft-link with several types of databases and models, including the LCA, to quantify energy and material requirements and environmental impacts simultaneously. Uniquely, they apply a hybrid LCA model (THEMIS) combined inputoutput framework with physical process lifecycle inventories.

Our prior studies focused only on nuclear power and the fuel cycle inventory at the global level (Tokimatsu and Kaya 2004) using an ESM, simply applying the Japanese nuclear fuel cycle database in Tokimatsu et al. (2006) (which generates Japanese nuclear power scenario manually, without applying ESMs), with minor modifications.

The primary merit of this type of analysis is that it can account for the time evolution (or dynamics) of inventories and the consequential impacts on the mid- and/or end-points of technology types, especially those that require massive energy in processing and operation, such as nuclear fuel cycles, and unlike those in which the most energy consumption is in the manufacturing stage (e.g., photovoltaic, wind).

The second approach, simply multiplying the factors, fully integrates LCA models with others by endogenously generating inventories from the ESMs and/or IAMs and then multiplying the factors from LCA models. This derives the metal requirements of power generation technologies on the lifecycle basis (Boubault et al. 2018), indirect energy consumption separated from direct energy in an LCA model (Arvesen et al. 2018) to apply global power generation mix (Pehl et al. 2018), and the environmental external costs (Tokimatsu et al. 2019).

Arvesen et al. (2018) conduct a methodological investigation in the precise separation of LCA factors for both direct and indirect allocation of energy consumption, compatible with the IAM framework. They applied the separated factors to two research directions: energy (Pehl et al. 2018) and endpoint impacts. These studies are similar to Boubault et al. (2018) in examining global power generation technologies; however, they chose the prospective and consequential LCA approach while Boubault et al. (2018) select the "allocation at the point of substitution" method and did not differentiate between the direct and indirect use of material flows and stocks.

The abovementioned LCA modes uncovered the third approach. Tokimatsu et al. (2016b) choose a soft-linkage approach, in which the model generates inventories, emission factors, and power production by multiplying the economic factors of LIME to obtain the time evolution of the costs and benefits of hypothetical power plant construction projects. Patrizio et al. (2017) apply background data from LCA (GEMIS, IMPACT), fully integrated as environmental external costs into a static ESM (BeWhere) without time evolution.

Some studies applying the cradle-to-grave lifecycle basis do not use system models; instead, they generate the scenarios manually (Stamford and Azapagic 2014; Santoyo-Castelazo and Azapagic 2014; Santoyo-Castelazo et al. 2014; Tokimatsu et al. 2006). Stamford and Azapagic (2014) assess power generation scenarios for the UK in 2070 in terms of the three pillars of sustainability: techno-economic, environmental, and social impacts. They use GEMIS, Ecoinvent, and Gabi as data sources. Other studies (Santoyo-Castelazo, Stamford, and Azapagic) are similar. Tokimatsu et al. (2006) develop their original Japanese nuclear power scenarios from 1960 to 2100 to show the time evolution of $\mathrm{CO} 2$ emissions and its intensity in the sector.

\subsection{Objectives}

Our study aims to show the future paths of endpoint damages caused by various impact categories at the global level in the twenty-first century and to offer a more comprehensive assessment of environmental impacts and resource use. The research question is as follows: what is the physical reduction in environmental impact (e.g., biodiversity) from a direct $\mathrm{CO} 2$ focused climate policy (i.e., 2DC target)? The impacts covered are global warming (GW), mineral resources (MR), land use and land-use change (LU), waste (WA), local air pollution $(\mathrm{AP})$, acidification (AC), and ozone depletion (OD). These impacts are due to resource management in all lifecycle stages (production, transformation, use, and end-of-use) of fossil fuels, uranium, metal (ferrous and non-ferrous base metals), non-metal (limestone), and bio-related products (agricultural products — rice, corn, and wheat - and wood products—-logs, wood pulp, and timber).

Our study is different from previous studies in that it adopts a fully integrated LCA model in its IAM. The term "fully integrated" does not imply the inclusion of the weighting process in LIME; it excludes the weighting process in the LCIA framework and, instead, emphasizes Dose-Response Function (DRFs). One reason for this exclusion is that the damages are not monetized and presented in their own units (e.g., 
Disability Adjusted Life Years (DALY) on human health $(\mathrm{HH})$ ), and the monetary process is unfamiliar for some readers. Another reason for this exclusion is that it disregards the internalization of the environmental external cost already published by us (e.g., Tokimatsu et al. 2019) and focuses on the DRFs to reveal future trajectories of endpoint damages that did not appear in our modeling exercises.

Since we exclude the weighting process and environmental external cost, this study uses a conventional (internal) cost minimization model that endogenously generates these paths. Our IAM is distinct from others in that it uses techno-economic ESMs due to its comprehensiveness. This study utilizes the latest version of impact assessment based on LIME3 and the inclusion of the mineral resource balance and the simplified land-use models. Moreover, we apply the newest scenarios in climate policy (2DC target) originally investigated under Ren 100 , based on our prior modeling exercises (Tokimatsu et al. 2018).

This paper is structured as follows: Sect. 2 explains our methodology, focusing on DRF scenarios that are modified and blended with our IAM. The subsequent sections discuss the study's results, discussions, and conclusions. Appendix 4 provides a list of abbreviations, whereby readers can better understand the manuscript. This study interchangeably uses words with similar meanings but different nuances without providing precise definitions (e.g., interlinked, in the title of Sect. 4.4).

\section{Methodology}

We focus on the global application of the LIME framework combined with our systems models: the overall model in Sect. 2.1, the resource balance models (i.e., systems models) in Sect. 2.2, adjustment of the DRFs in LIME in Sect. 2.3, connection of adjusted LIME and the other models in Sect. 2.4, and scenarios in Sect. 2.5. Finally, we discuss the strengths and weaknesses of our strategy in terms of model choice in Sect. 4.3.

For brevity and the ease of understanding, Appendices 1 to 4 contain the following details: the original modelthe case before the global application of the LIME framework; details of DRFs; three resource balance models (Tables 2, 3, and 4; Fig. 1); and a list of abbreviations, parameters, subscripts, and variables. LIME is an LCIA method that includes the three main steps of LCIA (i.e., characterization, damage assessment, and weighting; see Appendix Figure 4). It determines the weights of fewer endpoints (damage-oriented approach), rather than impact categories requiring 10 items or more, using the economic evaluation methods.

\subsection{Overall model illustration}

In the prospective LCA, various ESMs/IAMs attempt to use such techniques for optimization, input-output, simulation, and general equilibrium, with different time spans (e.g., 2030, 2050, and 2100) and geographical coverage (i.e., country, region, and global). We developed a dynamic optimization model (i.e., minimize the sum of the discounted supply costs) with a computation time horizon from 2010 to 2150 with 10-year intervals and for 10 world regions.

Figure 1 illustrates our overall modeling frameworks. The DRFs, as illustrated by arrows, connect the inventories in blue to the four endpoints in yellow (see also Table 1). With the weighting process excluded in the yellow box (LIME2 and LIME3), this study focuses on the direct, consequential damages at the endpoints of the inventory inputs in their physical units rather than in monetary units. The inventories are endogenously generated (only Ozone Depletion Substances (ODS) is given exogenously) from the four models in the blue box; namely, the simplified climate and the three resource balance models (energy systems, mineral resources, and bio-resources with land-use).

The objective function of this model is to minimize the sum of the discounted supply costs (including investment and fixed and variable operation and maintenance; see Appendix 3) of the resources over time from the three models (excluding the simplified climate). This setting implies that the world economy pursues economic efficiency. As environmental outcomes become significant social concerns, these are constrained or controlled; for example, greenhouse gas emissions or temperature increases caused by climate change. However, economic activities (i.e., resources production) are still adjusted according to constraint or control via their (private) cost minimization; thus, they do not internalize external environmental costs monetized from the outcomes.

We leave the investigation into weighting and internalization to other studies (Itsubo et al. 2018; Tokimatsu et al. 2016a; Murakami et al. 2018; Tokimatsu et al. 2019). We excluded the internalizing external environmental costs - our original approach using LIME - to follow other studies to present the similarities and disparities of our results.

\subsection{Three resource balance models}

The resource balance models are formulated through linear programming by dynamic optimization according to perfect foresight (i.e., demand and unit cost of variables are given deterministically) to minimize the discounted supply costs covering the overall lifecycle of resources and fully integrated bottom-up technologies. Other studies contain the details of the models (Tokimatsu et al. 2016c, 2017a, 2017b). Appendix 3 describes the model linkages, objective functions, and variable lists. 


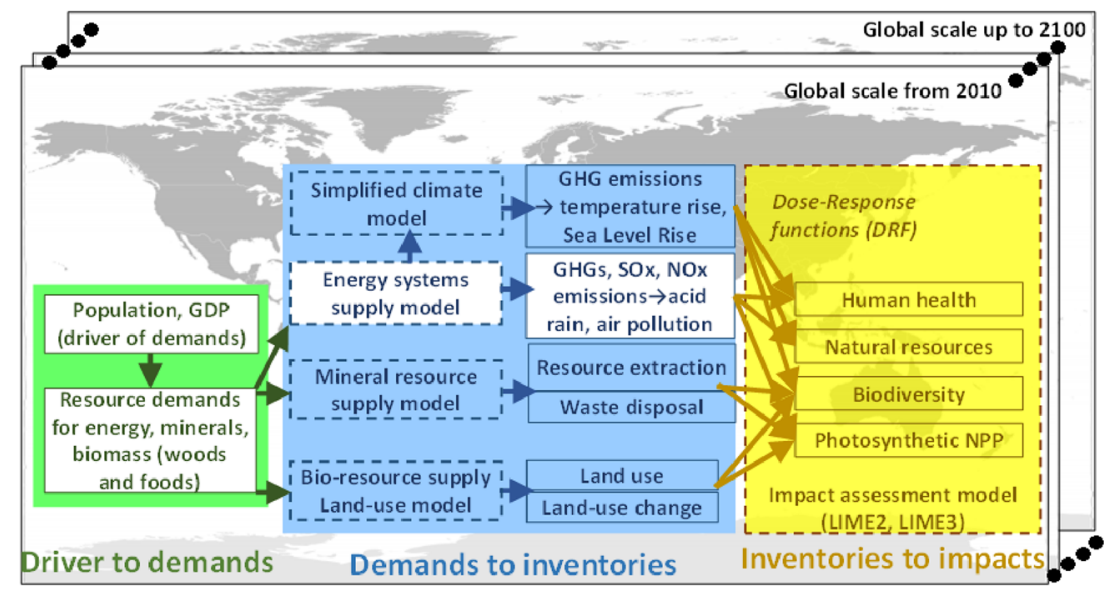

Fig. 1 Overall structure of our IAM used in the current study. Doseresponse functions (DRFs), which are illustrated by arrows, connect the inventories in blue to the four endpoints in yellow. The inventories are endogenously generated (except Ozone Depletion Substances (ODS), which is given exogenously) from the four models in the blue box, that is, the simplified climate model and the three resource balance models (energy systems, mineral resources, and bio-resources with land use). The white boxes are the compartments used by existing studies; most of them use energy systems models (ESMs) and midpoint impacts in a specific country or region till the middle of this century, whereas all the others shown in blue and yellow (including mineral resources and bio-related resources with endpoint impacts) are extensions of our global scale model that is valid up to the end of this century.

agricultural (rice, corn, and wheat; pork, chicken, lamb, and beef) and wood-based products (paper, wood lumber, boards, and fuel) based on five land patterns and its changes. These models express "balance" by supplying the resources to satisfy the demand generated from exogenously provided gross domestic product (GDP) and population scenario (i.e., SSP-2). Therefore, these models are not of the "general equilibrium" type nor do they encompass all sectors; however, they present sufficient resolutions for their consequential impacts.

Table 1 DRF connecting inventory-impact category-endpoint in our model

Models to generate inventory endogenously LIME model framework (excl. weighting)

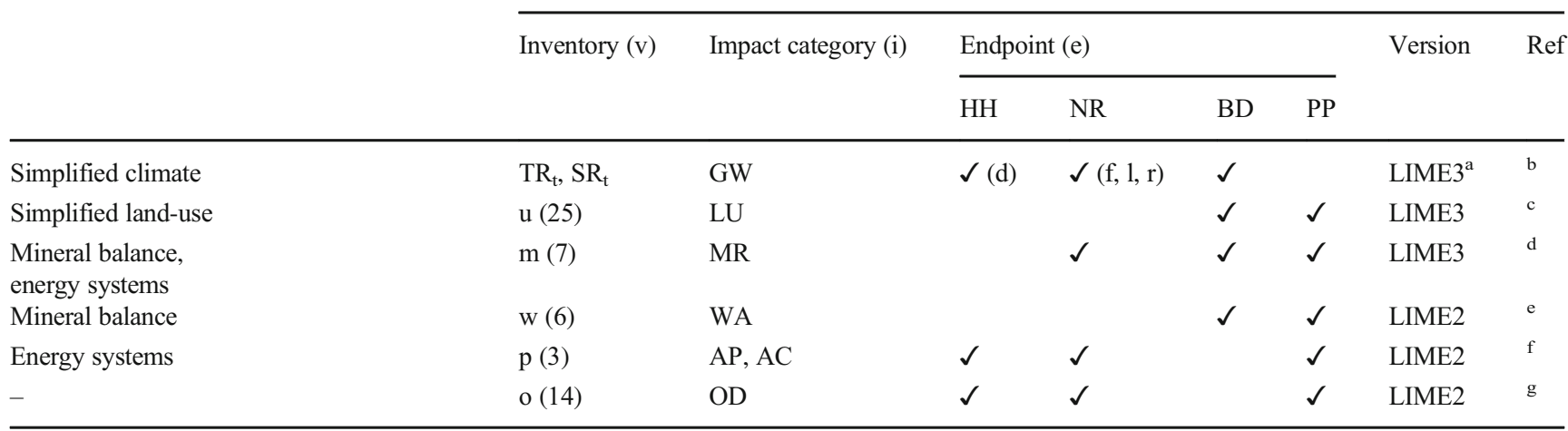

See Appendix 4 for abbreviations

${ }^{a}$ Exception; NR in GW is based on LIME2

${ }^{\mathrm{b}} \mathrm{HH}$ by Tang et al. 2018a, Tang et al. 2019; BD by Tang et al. 2018c, Tang et al. under review

${ }^{\mathrm{c}}$ Itsubo and Inaba 2018

${ }^{\mathrm{d}}$ Itsubo and Inaba 2018

${ }^{\mathrm{e}}$ Itsubo and Inaba 2014

${ }^{\mathrm{f}}$ Itsubo and Inaba 2013

g Itsubo and Inaba 2012 
The models on energy systems and mineral balance determined the flow and stocks of energy and material using the least-cost mechanism over their lifecycle. In the simplified land-use model, the allocations of resource flow are provided by parameter settings, whereas the amount of produced resources is determined by the area's costs for land use, landuse changes, and production yields. The three resource balance models endogenously generate inventories related to resources (production, disposal, land use, and land-use changes) and their consequential outcomes (emissions of GHGs, NOx, and SOx), where increases in temperature and the sea level as a result of global warming are computed ex-post by the simplified climate model. The generated inventories (shown in blue in Fig. 1) are given to the DRF, corresponding to the arrows shown in the yellow part of the figure, to calculate the four endpoint damages.

\subsection{Adjustment of the Dose-Response Functions in LIME frameworks}

\subsubsection{Outline of DRFs}

The DRFs are generally expressed in the following aggregated forms (see details in Appendix 2) to modify the factors $\left(D C_{j}\right)$ provided by LIME2 $\& 3$, using the terms $\left[A_{j, t}, B_{t}\right]$ to apply our IAM:

$$
\begin{gathered}
D R_{e, i, j, t}=D F\left(y_{j, t}, T R_{t}, S R_{t}\right)_{e, i} i=G W \\
D R_{e, i, j, t}=D C_{e, i, j, i} \cdot A_{j, t} \cdot B_{t}\left(\beta\left(T R_{t}\right)\right)_{e=B D} i \neq G W \\
A_{j, t}=\left[\left(\frac{P D_{j, t}}{P D_{j, 2000}}\right)_{e=H H} \cdot\left(\frac{y_{j, t}}{y_{j, 2000}}\right)_{e=N R} \cdot\left(\frac{P N_{j, t}}{P N_{j, 2000}}\right)_{e=P P}\right]_{i \neq G W}(3) \\
\cdot\left(\frac{O D_{j, t, m=C u, P b, Z n}}{O D_{j, 2000, m=C u, P b, Z n}}\right)_{i=M R}^{-1} \cdot S\left(\alpha_{j}\right)_{e=B D, i=W A}
\end{gathered}
$$

The first term $\left(D F_{j, t}\right)$ represents the damage functions expressed by per capita GDP $\left(y_{j, t}\right)$, global mean temperature rise $\left(T R_{t}\right)$, and sea level rise $\left(S R_{t}\right)$. This corresponds to the damage functions $(D F)$ for global warming $(G W)$ at all endpoint impacts (i.e., human health $(\mathrm{HH})$, natural resources (NR), and biodiversity (BD)).

The second term $\left[D C_{j} \cdot A_{j, t} \cdot B_{t}\right]$ denotes the damage of all impact categories other than $\mathrm{GW}$, with damage factors $\left(D C_{j}\right)$ and their adjustment terms $\left(A_{j, t}, B_{t}\right)$. The damage factors (i.e., constant level) are sourced from their lists provided in LIME2 and LIME3.

Since these lists include the environmental damage of either almost all the countries (LIME3) or Japan alone (LIME2), the first term $A_{j, t}$ reflects the order of magnitude of the endpoint damage in accordance with the Shared Socioeconomic Pathway (SSP) (van Vuuren et al. 2012). It follows that (i) population density $\left(P D_{j, t}\right)$ for $\mathrm{HH}$, (ii) per capita $\operatorname{GDP}\left(y_{j, t}\right)$ for $\mathrm{NR}$, and (iii) primary productivity (PP) and potential NPP $\left(P N_{j, t}\right)$ are determined by the Chikugo model (Uchijima and Seino 1985) using temperature and precipitation data from the Model for the Assessment of Greenhouse Gas Induced Climate Change (MAGICC) (Wigley 2010). These adjustments, which correspond to the first bracketed term in Eq. (3), are ratios of those levels in the target year and region divided by the values in the year 2000 (for Japan and in the LIME2 case). In addition to this ratio adjustment, two further adjustments are required $\left(O D_{j, t}\right.$ in the second term) for MR (using LIME3) and $\left(S\left(\alpha_{j}\right)\right.$ in the third term) BD in WA (LIME2), the former for ore degradation $\left(O D_{j, t}\right)$ over time in copper, lead, and zinc and the latter $\left(S\left(\alpha_{j}\right)\right)$ by a ratio of population density of endangered species in the target country divided by the values for Japan, corresponding to the second and third terms in Eq. (3), respectively.

The $B_{t}$ term expresses the increase in biodiversity impact in accordance with the reduction in area $\beta\left(T R_{t}\right)$ of natural land (i.e., forestland and grassland) through the land development by $T R_{j, t}$. This adjustment is required to determine the biodiversity impact in any impact category (i.e., mineral resources (MR), land use and land-use change (LU), and waste (WA)).

\subsubsection{Damage functions for global warming impacts}

The damage in HH (unit; DALY) is formulated based on population number $N_{j, t}$ [cap], the number of deaths [DALY/cap], the baseline mortality rate [\%] (because socioeconomic and demographic changes disregard global warming), relative risk $\left[(\% / \%) /{ }^{\circ} \mathrm{C}\right]$ due to $T R_{t}\left[{ }^{\circ} \mathrm{C}\right]$, and the percentage suffering from diseases. Both the damage per number of deaths and the baseline mortality are expressed as functions of $y_{j, t}$. The damage factors in HH are sourced from Tang et al. (2019), which have been revised based on the lists in LIME3.

The damage in NR can be broken down into the following three areas: agricultural products, land resources of submerged land area created via the $S R_{t}[\mathrm{~m}]$, and energy resources according to ambience (i.e., cooling, heating). The damage function is formulated from damage factors $\left[\right.$ ton $/{ }^{\circ} \mathrm{C}, \mathrm{km}^{2} / \mathrm{m}$, degree day $/{ }^{\circ} \mathrm{C}$ ] per unit increase in $T R_{t}$ and $S R_{t}$, multiplied by their increase. For energy resources, the relative increase in damage is also adjusted by degree days, heat demand GDP intensity, and per capita energy consumption expressed by functions of $y_{j, t}$. Unlike other endpoint impacts, their physical units are converted into monetary terms by multiplying their values with the market prices in LIME3. To reflect this notion, combining our resource balance models, we use shadow prices obtained endogenously, except for land area.

The damage factors in BD are sourced from Tang et al. (under review), which was revised based on the lists in LIME3 for the biodiversity impact of global warming $\left(D C_{j, i}=G W, e=B D\right)$ [EINES/yr] on a grid (approximately $10 \mathrm{~km}^{2}$ ). From this, we aggregated our regional damage factors. 


\subsubsection{Damage factors for impacts other than global warming}

The impact categories included here are MR, LU, WA, AP, $\mathrm{AC}$, and OD. The PP is a common endpoint for all impact categories, while $\mathrm{BD}$ is for $\mathrm{MR}, \mathrm{LU}$, and $\mathrm{WA}$; $\mathrm{HH}$ and $\mathrm{NR}$ are for AP, AC, and OD (see Table 1). The damage factors are sourced from LIME3 for MR and LU, while the others are from LIME2. The ore degradations in copper, lead, and zinc are tied to cumulative mine production, endogenously computed in a mineral balance model and integrated into our overall model over time. This degradation leads to the discharge of huge overburdens of deep mining and land development, resulting in the damages on $\mathrm{PP}$ and $\mathrm{BD}$.

The damage factors $\left(\mathrm{DC}_{\mathrm{j}}\right.$ in Eq. 2$)$ are divided into two terms. One is atmospheric concentration rise (e.g., NOx, SOx) by emission increase (denoted as $\mathrm{dC} / \mathrm{dE}$ ) and the other is DALY loss by atmospheric concentration rise (dDALY/dC). Hence, the DALY loss by increased emissions is expressed as follows:

$$
(\mathrm{dDALY} / \mathrm{dE})=(\mathrm{dDALY} / \mathrm{dC}) \cdot(\mathrm{dC} / \mathrm{dE})
$$

The first term, $\mathrm{dC} / \mathrm{dE}$ (concentration increase by unit emission), is developed by employing both the plume and puff models, which assume a linear relationship between concentration and emission (note that "substance emission speed" is used instead of "emission" in these models), while a nonlinear assumption was made between concentration and local weather conditions (e.g., wind direction, wind velocity, and atmospheric stability). In the development of LIME, $\mathrm{dC} / \mathrm{dE}$ is weighted average of results by the model calculations under the three weather conditions; however, the adjustment overlooks the condition changes in location and point in time, implying that adjustment of this term $(\mathrm{dC} / \mathrm{dE})$ simply follows the employed models.

The second term (dDALY/dC) is divided into the following three terms:

$\mathrm{dDALY} / \mathrm{dC}=(\mathrm{d}($ death or disease $)$ rate $/ \mathrm{dC}) \cdot($ population density $)(5)$

\section{$\cdot(\mathrm{DALY} /($ death or disease $))$}

Each term has the following units: (case person ${ }^{-1} \mathrm{yr}^{-1} \mathrm{mi}^{-}$ cro-g ${ }^{-1} \mathrm{~m}^{3}$ ), (person $\mathrm{m}^{-2}$ ), and (DALY case ${ }^{-1}$ ); hence, $\mathrm{dDALY} / \mathrm{dC}$ has the unit (DALY $\mathrm{m}^{-2} \mathrm{yr}^{-1}$ micro-g ${ }^{-1} \mathrm{~m}^{3}$ ). The first term, "contribution of concentration to increase of rate of death or disease," is a constant, implying that death or disease rate is linear and proportional to concentration and that it is common across background socioeconomic scenarios. The third term, "DALY per death or disease" is also independent from the scenarios, while only the second term, population density, is directly linked with the scenarios. This is why is the population density is adjusted $\left(A_{j, t}\right.$ in the Eq. 3$)$.

\subsubsection{Adjustment for biodiversity}

$B\left(\beta\left(T R_{t}\right)\right)$ is required for all $\mathrm{BD}$-related impact categories, while $S\left(\alpha_{j}\right)$ is used only for WA based on LIME2. $S\left(\alpha_{j}\right)$ is an adjustment term between the Japanese values and the target region, regarding the increase in extinction risk of certain species, where $\alpha$ is the ratio of population density of the endangered species in the target country, divided by the Japanese values. We found correlations between the numbers of endangered species and their increased risk per 1 ha. To simplify the regression analysis, we used domestic mesh data $\left(10 \mathrm{~km}^{2}\right)$ in numbers between those listed in the Red Data Book and the increase in the extinction risk of Japanese vascular plants identified by the environmental impact assessments. The function $S\left(\alpha_{j}\right)$ is calibrated using Japanese soil and gravel industry data (Itsubo and Inaba 2014).

$B$ denotes the extinction risk increase on a cumulative basis from the original state to a particular point in time. Since the extinction risk is expressed by a log-linear relation with the number of vascular plant species in the Japanese Red Data Book, $B$ can be derived by an integral up to the area change ratio $\beta$ (between two states: the current and original) being proportional to the number of species. We adopt three relational patterns between extinction species and $\beta$ from Thomas et al. (2004); the best data were chosen to tie with the corresponding temperature rise $\left(T R_{t}\right)$.

\subsection{Connecting Dose-Response Functions with inventories generated endogenously from other models}

The overall endpoint damages $\left(E D_{e, i j, t}\right)$ are generally expressed as the following aggregated form: (1) for $\mathrm{GW}, D R_{e, j, t, i=G W, v}$ is a direct route of $T R_{t}$ and $S R_{t}$ (interpreted as parts of inventories) from the simplified climate model; (2) with the exception of GW, $D R_{e, j, t, i=G W, v}$ is multiplied by the inventories $\left(I n v_{j, t, i \neq G W, v}\right)$ unrelated to GW after summing all the inventories (v). We then generate consequential endpoint damages using DRF.

$$
\begin{gathered}
D R_{e, i, j, t, v}=\left\{\begin{array}{cc}
D F\left(y_{j, t} T R_{t} S R_{t}\right)_{e, i, j, t} & i=G W \\
D C_{e, i, j, j, t} \cdot A_{j, t} \cdot B_{t}\left(\beta\left(T R_{t}\right)\right)_{e=B D} & i \neq G W
\end{array} ; \operatorname{DRF}(E q .1 ; i=G W) \operatorname{and}(E q .2 ; i \neq G W)\right. \\
E D_{e, i, j, t}=\left\{\begin{array}{cl}
D F_{e, i, j, t} & i=G W \\
\sum_{v} D R_{e, i, j, t, v} \cdot I n v_{i, j, t, v} & i \neq G W
\end{array} ;\right. \text { endpoint damages }
\end{gathered}
$$


Appendix 2 contains detailed specific formulations. For $\mathrm{GW}$, formulations are given to each endpoint (i.e., $\mathrm{HH}, \mathrm{NR}$, and $\mathrm{BD}$ ). NR is further divided into three resources (i.e., agriculture, land, and energy) to which formulations are given. Except for GW, damage factors from LIME2 and LIME3, which are created to multiply inventories, are simply multiplied.

\subsection{Scenarios investigated by this study}

Our 100 renewable energy scenario (Ren100) was developed from an energy scenario dominated by gas and renewables after allowing additional settings and assumptions. These are as follows: (i) radical expansion in the allowable maximum share of renewables in the power sector, (ii) phase-out of nuclear and fossil fuel in the production of hydrogen and liquid fuel, in addition to the power and heating sectors by 2100 (Tokimatsu et al. 2018). The Ren100 scenario was considered inherently incompatible with nuclear power; hence, the nuclear phase-out is in addition to the phase-out of fossil fuels in the energy sectors. To our knowledge, detailed $100 \%$ renewable energy scenarios have not been adequately addressed at the global level (Føyn et al. 2011; Hong et al. 2015), although there are many such studies at local or national levels (Connolly et al. 2011; Krajačic et al. 2011; Liu et al. 2011; Mathiesen et al. 2011; Østergaard et al. 2011a, b).

Based on the Ren100 scenario, the two climate policy scenarios are as follows: (1) business as usual (BAU) with no emission control on GHGs (including non-carbon GHGs), and (2) 2DC. Cumulative emissions in 2DC are zero over the computational time horizon (from 2010 to 2150) allowing the offset of peak-out and negative emissions by giving the $350-\mathrm{ppm}$ scenario cumulative emission constraints from Wigley-RichelsEdmonds (WRE) (Wigley et al. 1996). We cap the cumulative emissions constraints in the 2DC and restart for computation from BAU solutions in each energy scenario. We computed these model runs for this study according to modifications in the model framework.

\section{Results}

\subsection{Inventories}

Figure 2 depicts the inventories that were endogenously generated from our three resource balance models interlinked with the simplified climate model. Earlier LCA+ESM studies provide inventories of coal, NOx, and SOx in Fig. 2b. None of the other inventories in Fig. 2 has appeared in earlier studies, and they are included for the first time in the current study, which is one of its novel aspects. Figure 2a indicates the climate-related inventories $(T R, S R)$ for global warming that was computed ex-post by GHG emissions from the three resource balance models. Figure $2 \mathrm{~b}$ shows the inventories $(\mathrm{m}$, $\mathrm{w}, \mathrm{p}$ ) endogenously computed from the models for mineral balance and energy systems plus exogenously given ODS scenarios (o). The left bar denotes the inventories for $\mathrm{m}$ (production of coal and limestone) and w (waste from concrete and metals) corresponding to the impact categories for mineral resources and waste, whereas the right bar indicates $\mathrm{p}$ (the pollution generated by NOx and SOx) for acidification and local air pollution, and o (ODS, negligible) for ozone depletion. Figure $2 \mathrm{c}$ represents inventory $\mathrm{u}$, the area of land-use patterns with the total amount (left bar) and areal changes from the 20 patterns in land-use change (right bar).

Our energy scenario is based on Ren100; hence, in Fig.2a, TR under BAU increases to $2.5 \mathrm{DC}$ and is simultaneously stabilized at $0.55 \mathrm{~m}$; further, Fig.2b depicts the lower rate of production of coal and limestone and shows a dramatically decreasing trend for the production rates of NOx and SOx. Figure 2c shows the expansion of forestland to absorb atmospheric $\mathrm{CO}_{2}$ or of biomass energy with carbon capture and storage to meet the 2DC target. We input all these inventories into the equations listed in Sect. 2 and Appendix 2 to derive endpoint damages.

\subsection{Endpoint damages}

Figure 3 depicts the impacts on all the four endpoints, with (a), (b), (c), and (d) corresponding to human health (HH), natural resources (NR), biodiversity (BD), and primary productivity (PP), respectively. Figure $3 \mathrm{a}$ is dominated by global warming (yellow), followed by local air pollution (orange) due to the emission of SOx from coal production and negligible ozone layer depletion. We exclude particulate matter, such as $\mathrm{PM}_{10}$ and $\mathrm{PM}_{2.5}$, since these cannot be endogenously estimated using our energy model.

Undernutrition caused by global warming has the largest impact since it has the highest baseline mortality rate. It is followed by malaria, coastal floods, and diarrhea. The overall damages seem almost stable over the timeline; regardless of the increase in temperature, the implication of damage per degree rise in temperature [DALY/deg C] shows a declining trend. One of the two reasons for the declining trend in the baseline mortality rate from onesixth to one-half is the increase in per capita income; thus, the values for malnutrition, diarrhea, and malaria are close to zero. The other reason is that the percentage in the total population is assumed to follow a dramatic declining trend in the SSP scenario for malnutrition and diarrhea, currently declining to $5 \%$ and $20 \%$ from $20 \%$ and $50 \%$, respectively, in the largest region.

Impacts other than global warming are determined by inventory levels, rather than damage factors; the emission level 


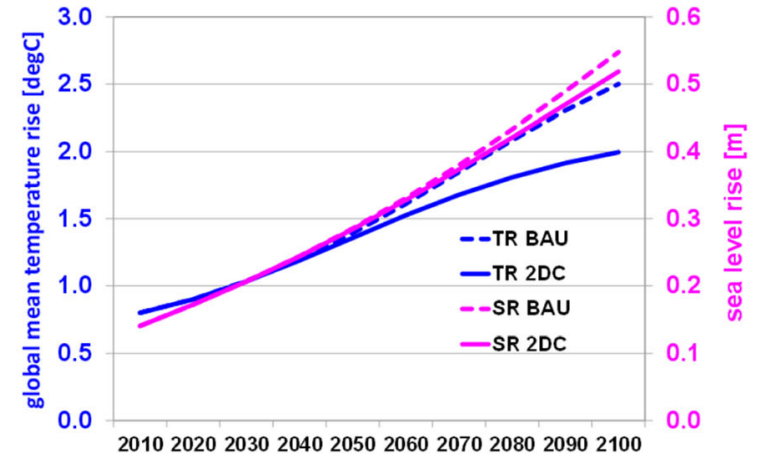

(a)
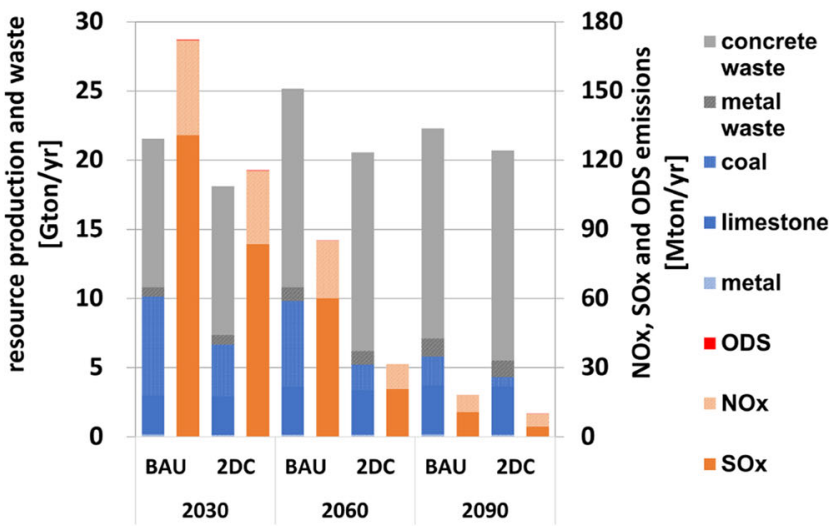

(b)
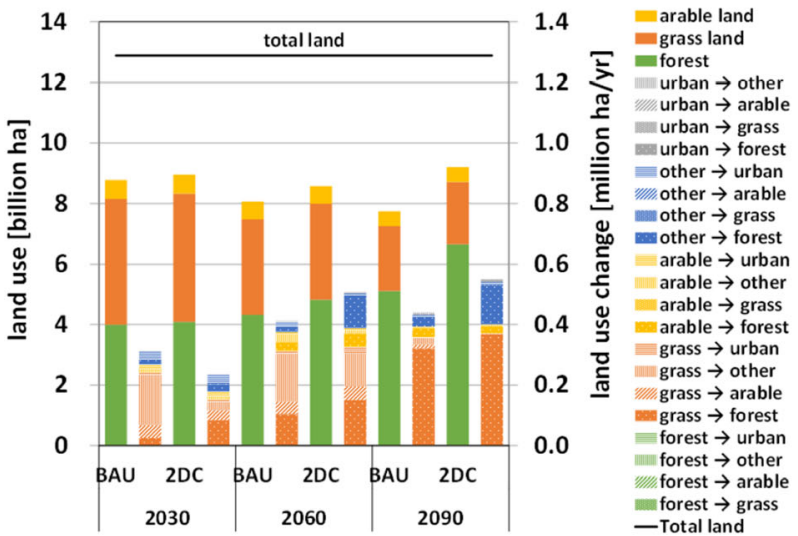

(c)

Fig. 2 Inventories endogenously generated from our IAM. a Climaterelated inventories for increases in temperature (TR; blue, left) and sea level (SR; pink, right) for both climate policy scenarios (BAU; dashed, 2DC; solid) generated from the simplified climate model by inputting the endogenously calculated greenhouse gas emissions of both $\mathrm{CO}_{2}$ and non$\mathrm{CO}_{2}$ using the energy systems model. These are not considered by existing LCA+ESMs studies. b Inventories of resource production and discharged waste (left axis); consequential emissions of ODS, NOx, and $\mathrm{SOx}$ (right axis) endogenously generated from the models for mineral balance and energy systems; and exogenously provided ODS scenario.

of ODS is $1 / 20$ of SOx and NOx. The impacts on local air pollution decline due to the phasing out of coal in the energy mix. A comparison of (a) global warming only (yellow parts),
Unlike existing LCA+ESM studies, which consider energy-related inventories (i.e., coal, NOx, and SOx) alone, our model includes the mineral resource model and expands other inventories, some of which are significantly high levels of inventories. c Areas in land use (left solid bar and axis) and land-use changes (right hatched) generated using bio-resources and the simplified land-use model. Three land-use patterns (from bottom to top: forestry, grassland, and arable land) are shown, which are the main causes of land-related damages. All 20 patterns are illustrated for land-use change, among which forest is dominant. These land-related inventories have not been mentioned by existing LCA+ESM studies

which is treatable according to existing LCA+ESM studies, and (b) the overall impacts shown in Fig. 3 revealed that the level of overall impacts declines (1) over time and (2) in 2DC 


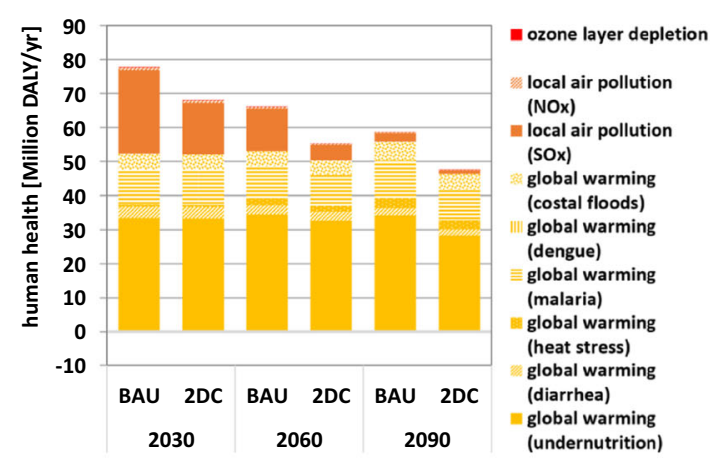

(a) Human health $(\mathrm{HH})$

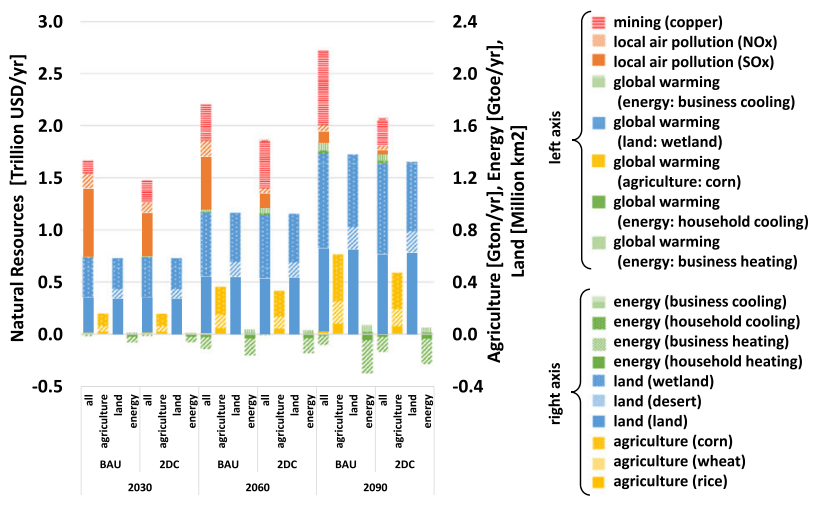

(b) Natural resources (NR)

Fig. 3 Four endpoints impacts. a Human health $(\mathrm{HH})$. From bottom to top: global warming (undernutrition, diarrhea, malaria, and coastal floods) and local air pollution (SOx). The impacts of global warming decrease with a decrease in the global mean temperature, whereas local air pollution is significantly reduced by the phasing out of coal in the energy mix. Although there are many publications on ESMs/IAMs that investigate co-benefit on local air pollution via climate change mitigation, they focus on reductions in GHG, SOx, and NOx emissions, and their cost-benefit analysis yields no results on endpoint damage to human health using common units (e.g., DALY). b Natural resources. The left most bar (all) corresponds to the left axis in monetary value, whereas the bars remaining to the right of the figure correspond to different nonmonetary units of natural resource impacts (agriculture, land, and energy). The total amount and value increase with the passage of time due to increases in temperatures, sea levels, and resource demand. No existing LCA+ ESMs study discusses endpoint impacts (i.e., agriculture, land, and energy in the right axis and their monetary values in the left axis). On comparing (a) global warming only (in blue, green, and yellow) with (b) other

compared with BAU due to the significant reduction in local air pollution in the beginning and the slight increase in global warming later. This observation is a novel aspect of our study and is obtained by the addition of models, other than ESMs.

In Fig. 3b, the bar on the far left of the graph presents natural resources damages in monetary terms, including the resource rental by user cost (left axis), whereas the damages to resources in agriculture, land, and energy in terms of ambience (from left to right) are in physical units (along the right

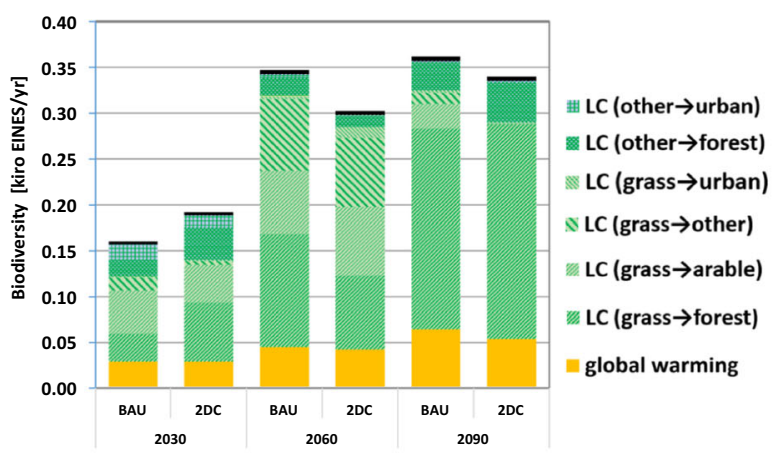

(c) Biodiversity (BD)
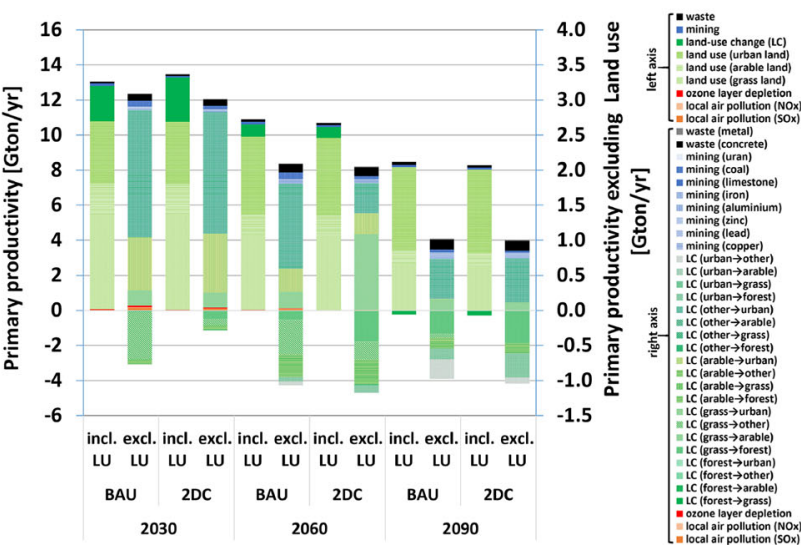

(d) Primary productivity (PP)

than global warming (local air pollution and mining, in orange and red) in this figure, we observe that, between BAU and 2DC, (1) global warming only shows little difference in the four columns, whereas (2) other than global warming (orange, red) in the "all" column (shown to the far left) indicates moderate reduction. c Biodiversity. From the bottom (global warming in yellow) to top (land-use change in green), the change of land-use type to forest becomes dominant. No results are provided in the figure legends of existing studies on ESM + LCA. Further, global warming (temperature increase) is sourced from the simplified climate model, land-use change (LC) from the land-use model, and mining and waste from the mineral model. d Primary productivity. In the left bar (incl. LU, left axis), all damages in primary productivity are dominated by land use in mainly urban land areas (human settlements) and grasslands. The value highlighted in the darkest green color at the top of the left bar is magnified in the right bar, excluding land use (excl. LU, right axis). Only local air pollution (NOx, SOx) can be treated in ESMs; all the other causes of impacts on the growth of plants described in the legends are newly added by our model

axis). The figure shows that the metrics are dominated by blue (damage to the land resource from global warming), followed by local air pollution and energy, whereas the others are invisible. The damage to land resource types (terrestrial or wetland) in monetary units is comparative because the larger proportion of submerged areas in terrestrial land has lower land cost. The shadow prices for copper and energy for heating are sufficiently high to reflect large-scale resource rental and energy resource damages, respectively, whereas the prices of 
agricultural products are sufficiently low to become invisible. On comparing (a) the energy related only (global warming and local air pollution, in blue, green, and yellow) by ESMs with (b) the others (ozone layer depletion and mining, in red) shown in this figure, we observe BAU and 2DC and clarify that (1) energy related shows little difference in the four columns, whereas (2) "other than local air pollution" (in red) in the "all" column (the extreme left) indicates moderate reduction. It is noted that independent studies on the impact assessment for each sector (i.e., agriculture, land, and energy) have been conducted on different and inconsistent backgrounds. In contrast, our results are consistent because they are generated by our own modeling, which is a strength of our study.

Figure $3 \mathrm{c}$ depicts all the biodiversity damages, most of them dominated by land-use changes (in green) and some by global warming (in yellow). Damage from global warming increases in accordance with $T R$. The LU from grassland to forest, arable land, and other land types has the largest impact since it represents the largest areal transformation and highest damage factors. Comparing (a) global warming only (in yellow) with (b) other than global warming (LC in green) in this figure, we observe that the overall impacts strengthen over time and 2DC is slightly smaller than BAU in global warming only, whereas there is a slightly larger difference between 2DC and BAU after 2060 regardless of the changes in the breakdown of LC (green). The addition of the green items in this figure is a novel aspect of our IAM.

Figure $3 \mathrm{~d}$ displays all the damages from primary productivity in the left bar (including LU, left axis); they are dominated by land use, particularly in urban land areas (human settlements) and grasslands because of the large area in use. The value highlighted in the darkest green color at the top of the left bar is magnified in the right bar, excluding land use (excluding LU, right axis), where positive and negative aspects generally correspond to other (unmanaged land) to urban (human settlement) and loss of grassland due to larger level damage factors. It is apparent that the energy-related impacts of ESMs (i.e., impacts of SOx and NOx on local air pollution; denoted in orange) are negligible, whereas all the other impacts are from the newly added models in our IAM.

\section{Discussion}

\subsection{Interpretation of our results in relation to extant literature}

To the best of our knowledge, no other study is directly comparable with ours. Therefore, it is important that we present the plausibility of our results. In this section, we interpret our results by comparing them with the general conclusions of other studies. We follow three endpoint results (Fig. 3): breakdown of human health, biodiversity, and comparison with other LCIA models.

The World Health Organization (WHO) conducts distinct studies on human health. Its Global Health Risks (World Health Organization 2009) considers environmental problems such as unsafe water, sanitation, hygiene, indoor smoke from solid fuels, lead exposure, urban outdoor air pollution, and global climate change. The World Health Organization (2009) predicts that the impacts of global warming and local air pollution on human health are comparable, and this prediction is similar to our findings. These impacts are highlighted by the World Health Organization (2014) and Lelieveld et al. (2015) in World Health Organization (2009). Lelieveld et al. (2015) estimate 3 million deaths, equivalent to 30 million DALYs, assuming 10 DALYs for one death. Our result for untreated primary particulate matter $\left(\mathrm{PM}_{2.5}\right)$ shows 20 million DALYs, which reflects Lelieveld et al. (2015) conclusion. On the impact of global warming, the $\mathrm{RR} /{ }^{\circ} \mathrm{C}$ employed in our analysis (Tang et al. 2019) was originally taken from WHO (2014). Hence, the impacts of local air pollution and global warming are comparable, but a little lower, owing to the omission of $\mathrm{PM}_{2.5}$.

Next, we consider biodiversity. In The Millennium Ecosystem Service (MEA 2006) and The Economics of Ecosystems and Biodiversity (TEEB 2012) reports, the main impacts on biodiversity are from land use and global warming. Many studies on biodiversity impacts are an assessment of extinction speed, while relatively few examine the LCA. The global number of species extinction is reported to be in the tens of thousands (Pereira et al. 2010), while our results show 200 to 400 species. Our breakdown shows that this extinction is the result of land use, which has a greater impact than global warming. This confirms the plausibility of our result. In the field of LCA, the LC-IMPACT (2019) model treats acidification and water resource for biodiversity impacts, which are beyond the scope of our modeling framework.

Finally, we describe the dependency of our results on the LCIA model. The results for the endpoints of our study are based on LIME, whose impacts must be similar when applying other models (e.g., ReCiPe (2018) or LC-IMPACT), since the three models have similar damage coefficients. Human health impacts from global warming in LIME (Tang et al. 2019) are of a similar order to those found by De Schryver et al. (2009), who employed ReCiPe and LC-IMPACT. Regarding biodiversity impacts arising from global warming, LIME only treats plant species, while ReCiPe includes multiple taxon. However, impacts from plant species alone are of a comparable order in both models (Tang et al., under review). Although results on the four endpoint impacts seem to change to some extent if impact assessment methods (e.g., ReCiPe (2018) or LC-IMPACT (2019)) are applied instead of LIME, we expect that the scenario comparison of BAU and 2DC are change to a limited degree. 


\subsection{Novel aspects of this study}

Here, we summarize the original aspects of this study in terms of the study's methodology, focus on LCA, and results sourced from the methodology.

\subsubsection{Methodology}

The key methodological originality of this study, compared with existing LCA+ESM studies, is that it extended the framework comprehensively (see Fig. 1) to include the (1) the simplified climate model, (2) the mineral resources model, (3) the simplified land-use model, (4) endpoint impacts by LIME, and (5) a hard-linked characteristic. Many of the existing studies employed ESMs such as TIMES/TIAM model families (see the review by Volkart 2017), which are not linked to the simplified climate model to compute rises in temperature and sea level; hence, GHG emissions from ESMs were combined with the LCI dataset (e.g., ecoinvent) in some studies (e.g., Volkart et al. 2018; Boubault et al. 2018) and/or with the LCIA model (e.g., ReCiPe) in others (e.g., García-Gusano et al. 2017a, b; Pehl et al. 2018).

\subsubsection{Focus on lifecycle assessment}

The studies discussed in Sect. 4.2.1 mostly focus on power generation technologies alone, whereas our study considers the overall GHG emissions from energy systems. A model for land use and land-use change has only been considered by Pehl et al. (2018), and it uses MAgPIE in a soft-linked manner; however, the authors consider GHG emissions alone in their assessment. Contrastingly, our study evaluates endpoint impacts on biodiversity and primary productivity in a hard-linked manner. Further, other studies did not use the mineral resource model, whereas our study is unique in that the mineral model (Tokimatsu et al. 2017b) is used in our framework.

The focus on LCA varies among studies. Some emphasize the cradle-to-grave nature of LCA, as well as indirect emissions in plant construction or embedded emissions during energy resource production and transport in LCI and both methodological investigation and model analysis (e.g., Pehl et al. 2018; Arvesen et al. 2018; Volkart et al. 2018), whereas other studies focus on the "outcomes" of using LCI or LCIA, such as metal requirements (e.g., Hertwich et al. 2015; Boubault et al. 2018) and endpoint impacts (e.g., García-Gusano et al. 2017a, b). Unlike the studies by Arvesen et al. (2018) and Weidema et al. (2018), this study does not focus on linking LCI and LCIA in mid-point damages.
By applying another impact assessment method, midpoint damages can be examined using more than 10 environmental categories (global warming, acidification, eutrophication, etc.; see García-Gusano et al. 2017a, b) in an uncomparable manner. Hence, it is impossible to compare scenarios by mid-point in a quantitative manner. On the contrary, it is easier to interpret results and compare various environmental issues by using an assessment of four endpoint damages, which was the method used in this study. One advantage to indicating the results using a single index by the weighting factors for four endpoints is that the cost-benefit can be expressed in monetary units. However, an inherent disadvantage is that this method has significant uncertainty caused by the (i) aggregation of multiple factors into a single index; (ii) omission of detailed and concrete environmental information; and (iii) use of methods such as interviews or surveys of the general public, which are more subjective approaches than natural science methods. Hence, showing results on four endpoints is a reasonable alternative.

\subsubsection{Results}

The originality of our results is based on the extension of our model framework. Most of the existing LCA+ ESM studies reveal results on the power generation technologies of their life stages (i.e., construction, operation, and decommission) related to their (in)direct LCI inventories (e.g., GHG emissions and metal requirement), whereas our study encompasses highly expanded and general inventories that are multiplied by damage factors modified from LIME3. Hence, the only overwrapping inventories are those from ESM (e.g., coal production and emissions of SOx and NOx); the remaining inventories, such as increases in temperature and sea level, material-related inventories (production of limestone and waste discharge), and land-use changes, are left untreated in existing studies. Only a few studies (e.g., García-Gusano et al. 2017a, b) examine the overwrapping endpoint impacts on human health and ecosystem services; contrarily, our study focuses more on natural resources (Fig. 3b) and primary productivity (Fig. 3d).

Moreover, apart from LCA+ESM studies, many publications on ESMs/IAMs investigate the co-benefit of climate change mitigation efforts on local air pollution (e.g., Bollen et al. 2010). They focused on reductions in GHG, SOx, and NOx emissions, and their cost-benefit provided no results in terms of endpoints for human health damage using common units (e.g., DALY; see Fig. 3a). Therefore, our results are not at all similar to the results of such co-benefit studies. 
Furthermore, most studies on climate change mitigation using ESMs/IAMs focused on policy assessment through scenario comparisons of economic efficiency or cost-benefit. Our results are based on not only climate change mitigation efforts and their co-benefit but also other impact categories, in terms of endpoint damages, which clarify that the impacts of mining, land use, and land-use change are significant, as well. Specifically, the 2DC scenario in this study, which heavily depended on renewables, promoted forestry and focused on trade-off by expending these efforts. We recommend that climate change mitigation efforts be assessed according to not only the efforts' direct effects but also more comprehensive perspectives on environmental issues.

\subsection{Question of balance regarding our Dose-Response Functions approach}

To apply the cradle-to-grave philosophy, a question of balance should always be addressed while margining large models to investigate the dynamic mode of LCA. We developed the damage factors in LCIA by adding the consequential damages divided by the released inventories (causes). We estimated the damages using detailed, specific models to conduct relevant impact assessments. The damages retained short- to long-term horizons depending on the impacts. Consequently, the damage factors intentionally eliminated time evolution to provide "averaged," aggregated damages per unit of inventory; thus, LCA practitioners can easily calculate damages using basic arithmetic. This is an extremely simplified aspect of our model for practitioners, whereas studies such as Arvesen et al. (2018) and Volkart et al. (2018) present much more complicated model.

LCIA models consistently provide multiple impact pathways in the linear form to assess potential impacts aggregated over time and space, instead of the actual impacts of a specific source on a specific receptor (endpoint). This is very different from the so-called damage functions in climate-welfare economy IAMs. IAMs with no specific relationships between the actual impacts of a specific source on a specific endpoint simply link the economic damage in GDP loss with a rise in temperature. Intrinsically, the investigation in the dynamic mode of LCA proceeds in the opposite direction such that it disaggregates the impacts. This disaggregation with time expansion is plausible, suitable, and compatible for long-lived, stock-based phenomena, such as global warming, whereas we do not expand on other impacts in our model and they remain unchanged to apply the factors. This is because our model has a 10 -year interval, which is sufficient to approximate the consequential impacts in practical LCA exercises.

Another dimension, besides time, is the spatial expansion that we explain here. The development of the damage factors covering 197 countries for the LIME3 also required huge resources (e.g., time, people, and budget). Our approach for the category impacts using LIME2 seems somewhat rough or adhoc, as we only adjust the levels of the endpoints by order of magnitude. The next step seems to be to adjust not only the endpoints but also make an additional amendment to the DRF or develop country-level damage functions, as in LIME3.

Skipping such strategies otherwise requires tremendous resources to operate all the models related to the impacts via soft-linkage, after blending the underlying socio-economic, energy, and climate policies. Hence, our adjustment of DRF in LCIA to be compatible with IAM is a well-balanced approach.

\subsection{Strengths and weaknesses of our approach}

Overall, our approach can provide more unique insights than those in "conventional" and "mainstreaming" approaches in both disciplines of LCA and IAM. In addition to the originality and comprehensiveness of this study, as described in Sect. 1.2 , this section highlights the strengths and weaknesses of our approach, mainly sourced from the LCIA modeling framework.

First, the strength of many European studies is in their technology assessments, in particular, in power generation analysis based on the New Energy Externalities Development for Sustainability (NEEDS) project (Schenler et al. 2008). This approach demonstrates the three pillars of sustainability - social, techno-economic, and environmentin detail, for power generation technologies. On the other hand, our Japanese approach has advantages in terms of comprehensive coverage of environmental impacts and resources and the weighting process based on LIME.

Second, we compute environmental damages on the four endpoints within the framework of LIME, consistent with scenarios in the model, although sectoral impact assessments (e.g., human health, agriculture, biodiversity) are more comprehensive. For example, comprehensive human health damage includes various causes unrelated to the environment, such as tobacco or alcohol use, which we exclude. Our analysis shows the sum of the impacts of both local air pollution and global warming over time under the same energy and climate scenarios, while sector impact assessments are conducted separately under uncommon scenarios and assumptions. The same elements correspond to other impact categories; hence, an advantage of our analysis is in its consistent assessment within (limited) environmentrelated damages under common and flexible scenarios and assumptions.

Regarding strengths and weaknesses, the former (strength) is available and traceable to the open-public method we developed in this research for modification of DRFs to apply 
open-public damage factors in LIME. Hence, our modified damage factors can be reproduced, even rearranged, to apply ESMs/IAMs or inventory scenarios borrowed from other studies. The weakness of our approach is its complexity, resource- and time-intensiveness, and closed-source nature, particularly as Vanderpaer and Gibon (2018) argue that the importance of views by and usefulness for LCA practitioners, open-source software, and data sharing are necessary for such prospective LCA studies.

Another weakness of our analysis is that it uses no common assumptions with the other "comprehensive" and "sectoral detailed" analyses. Thus, our results will be difficult to validate or compare with similar or related studies. For example, some studies investigate $100 \%$ renewable energy with the 2DC target settings investigated here. Moreover, our methodology for impact assessment, DRF, seems to be similar to those employed in FUND; however, distinctive differences in the LIME framework separate the damage assessment in physical terms from the monetary valuation, by employing the weighting process (i.e., damage assessment in monetary terms). However, in contrast to this study, the FUND model incorporates highly aggregated damage functions in monetary terms, neither at the endpoints nor in physical units.

\subsection{Co-benefit of climate policy: outcome of interlinking models of lifecycle assessment and integrated assessment}

This article focuses on integrating models of integrated assessment and lifecycle assessment. This section describes another outcome in addition to that in Sect. 4.3 (specifically, dynamic impact assessment). The other outcome is to show the cobenefit from global warming mitigation. We prepared two sets of climate policies, BAU and 2DC, using the cumulative emission cap. This results in transformation of energy for reducing GHG emissions and land-use changes for absorbing and releasing carbon through forestry. Reduction in GHG emissions lowers the coal consumption rate, which, in turn, reduces the SOx and NOx emissions. The decrease in coal consumption rate then brings co-benefits in addition to global warming for greater reduction in human health impacts in 2DC than in BAU (see Fig. 3a). The increase in the forestry area implies that the transformation of other land-use patterns is suppressed, leading to relative reduction in biodiversity (Fig 3c). On the contrary, impacts on natural resource (Fig. 3b) all relate to global warming; hence, we can expect no co-benefit.

\section{Conclusions}

This study illustrates the future paths of the four endpoint damages on a global level over this century, caused by various impact categories endogenously tied to our hard-linked, fully
Integrated Assessment Model. This study describes the DRFs while excluding the weighting process in the LCIA framework. Further insights, not discussed here, can be identified, especially in terms of sustainable development aspects. We leave these to the other studies mentioned in the introduction section. The studies in the XLCA modes (i.e., LCA and ESMs, IAMs) promise that they can provide unforeseeable and fruitful insights.

In recent decades, there have been suggestions to use the models for LCA and systems analysis (Jolliet et al. 2004); however, this has led to some controversy, especially in the weighting process in the LCIA framework (Hordijk 1995). Stimulated by such controversy, we have pioneered studies in this area. Currently, the situation seems to have dramatically changed with many studies published, triggered by the NEEDS project, which is expected to widen the XLCA modes. The strength of the European studies lies in technology assessment, especially power generation based on the NEEDS project, while our Japanese studies have advantages in their comprehensive coverage of environmental impacts and resources and the weighting process based on LIME.

LIME3 is a "modeling methodology," not software, and it provides "lists of damage factors, weighting factors, and economic factors" and is downloadable from Itsubo and Inaba (2018). Adding another category requires further investigations based on the modeling framework; hence, in this regard, it is inflexible. However, this article described the precise details of the application to our IAM, which can also be useful to any ESM/IAM. The ESM side requires an open source tool (e.g., OSeMOSYS) for better researcher engagement. Such trends seem to have accelerated over the past several years after being handled by closed scientific communities for decades. The authors believe XLCA modes studies may significantly contribute to expanding our understanding of society. We strongly encourage research scientists in both disciplines to participate in studies on the XLCA modes.

Acknowledgements The first author expresses his sincere appreciations to all who gave comments on our manuscript, including anonymous reviewers. This work was partially supported by KAKENHI (18K11736), the National Institute of Advanced Science and Technology (AIST), the Takahashi Industrial and Economic Research Foundation, the Egyptian Ministry of Higher Education (MoHE) and related funds. He would like to thank Editage (www.editage.com) for English language editing.

\section{Appendix 1. Lifecycle impact assessment method based on endpoint modeling}

1. Outline

LIME is a well-known bottom-up leading method in LCA studies. Previous versions (LIME1 and LIME2) were based 
on Japanese conditions and modeling; however, the latest version (LIME3; LCA Society of Japan 2019; Itsubo et al. 2018) was developed on a global scale. Details of the model developments via the three steps can be found in the literature cited elsewhere in this study, as such descriptions cover several hundred pages and are outside the scope in this study, especially LIME2 (Itsubo and Inaba 2012, 2013, 2014).

LIME3 enables the comparison and aggregation of environmental impacts among 193 countries on a global scale. These include global warming, air pollution, photochemical ozone creation, water use, fossil fuel, mineral resources, and forest resources tied to land use (those underlined are included in our model here). We calculated the damage factors, connecting potential damages of the four endpoints with a unit amount of inventory release on the country-to-country basis of 193 countries, using the dose response function (DRF).

\section{LIME3 in our IAM}

In this study, damage by global warming is based on LIME3 for human health and biodiversity, including further investigations and modifications by Tang et al. (2019), while natural resources are sourced from LIME2 (Itsubo and Inaba 2012). The damage caused from $\mathrm{CO} 2$ emissions was calculated for each disease (malnutrition, diarrhea, cardiovascular disease, malaria, and coastal and inland flooding) (Tang et al. 2018a; Tang et al. 2019). Biodiversity damage from climate change was assessed by statistical analysis of vegetation distribution changes of 250 species of plants in Japan (Tang et al. 2018c); however, Tang et al. (under review) have expanded the grid data used to over 280 thousand taxa (see Appendix 2).

Damages from global warming to crop production (rice, wheat, and corn) and energy resource consumption is categorized by ambience (cooling or heating) in terms of global mean temperature increase and for land resources, in terms of submerged areas (onshore, wetland, tundra, and desert) by increase in sea level. The damage to resources (crops, energy) is valued using shadow prices obtained in our three resource balance models, while those for areas are referenced from Fankhauser (1998).

Damages from land use and land-use change to biodiversity in LIME3 were assessed using the incremental risk of extinction of 2000 species of vascular plants in Japan, as per each type of land use and transformation (Yamaguchi et al. 2018). We adopted Yamaguchi et al.'s (2018) methodology for 193 countries, using International Union for Conservation of Nature and Natural Resources (IUCN) data. Land-use damage to primary productivity is measured as the differential between potential NPP and current NPP, using the landuse pattern at the country level, which is disaggregated into the country level from those at the global level (Haberl et al. 2007) after identifying overlapping global vegetation patterns and national borders. LIME provides the following definitions for this impact category. Inventories in land use and land-use change are areas in occupation (or appropriation) in certain patterns (e.g., forestry) and in changes (e.g., from forest to human settlement). The time for appropriation of land use is assigned to every land-use pattern, while the time for restoration to arrive at the original productivity level is given in land-use change. Damages by these focused on degradation of potential NPP and increasing risk of extinction for vascular plants (disregarding numerous impacts associated due to a lack of qualitative information for impact assessment).

Damages by mineral resources in LIME3 are assessed for three endpoints (natural resources, biodiversity, and primary productivity). The natural resources are valued using the user cost method. The mining-transformed land area consists of the mine site, the deposit site from accumulated overburden discharged from mining, and the waste disposal site for tailings generated from ore concentration and coal pretreatment. This transformed area is formulated in terms of weight of mined resources, ore grade, ore body thickness, and the socalled hidden flow. The number of endangered species and primary productivity are estimated based on the transformed area. The above modeling is based on country and regional data aggregated from site-specific data such as mining method (underground, surface), ore body thickness, and ore grade.

Our modeling does not address the following damages in LIME3. The trans-boundary effects were taken into account for $\mathrm{PM}_{2.5}$, both primary and secondary produced air pollutants (i.e., SOx, NOx, black carbon, and organic carbon) (Tang et al. 2018d) and photochemical oxidant substances (Tang et al. 2018b) using a global chemical transport model. Agricultural irrigation water constrained by freshwater consumption was combined with malnutrition damage by crop production loss through irrigation, via global changes in food production and trade (Motoshita et al. 2018).

\section{LIME2 in our IAM}

The following damages included in our model are based on LIME2: waste (Itsubo and Inaba 2014), local air pollution and acidification (Itsubo and Inaba 2013), and ozone layer depletion (Itsubo and Inaba 2012). Damage factors for waste are only included in biodiversity and primary productivity at landfilling sites in the final disposal of metallic and cement waste. These are considered relatively common in countries other than Japan, although the damage factors provided for numerous types of waste in LIME2 are more countryspecific damage estimates. Discharged wastes are converted to area changes for the landfilling site, which is transformed into endpoint damages in a similar manner as mineral resources. 
The following damages are included: local air pollution (on human health) by both SOx and NOx, and acidifications (on natural resources and primary productivity) by NOx. For local air pollution, respiratory disease is caused by an increase in pollutant concentration in SOx (immobile, point source from chimney) and NOx (both immobile and mobile from automobiles), both as primary and secondary pollution, through emissions. The concentration increase in emissions is computed for both short $(0.2-20 \mathrm{~km})$ and long $(200-2000 \mathrm{~km})$ distances with a source-receptor relationship (SRR).

For the acidification via acidic deposition from the air to the natural environment (terrestrial surface ground, and sea), terrestrial vegetation for primary production, and wood and fishery production (catch of Salmonidae) for natural resources are included in LIME2 (i.e., hard to quantify impacts, such as cultural assets, are excluded). Examples of main acid substances emitting hydrogen ion $\left(\mathrm{H}^{+}\right)$are sulfuric acid $\left(\mathrm{H}_{2} \mathrm{SO}_{4}\right)$ and nitric acid $\left(\mathrm{HNO}_{3}\right)$, which are changed via an alteration process from emissions of SOx and NOx, respectively. Those substances are deposited into the natural environment via dry gaseous, particulates or wet precipitation, such as rain. An increase in acidic deposition via computed SRR is used to evaluate increasing endpoint impacts. Decrease in the primary production rate is through an increase in the soil solution $\mathrm{Al}^{3+}$ caused by a $\mathrm{pH}$ decrease in soil solution, whereas the Salmonidae decrease is through the lowering of the intrinsic growth rate via a $\mathrm{pH}$ decrease in land water.

The damages from ODS in LIME2 are human health (skin cancer, cataract), natural resources (production in agriculture and wood), and primary productivity (both terrestrial and aquatic ecosystems). ODS emissions improve results, with an increase in UV-B reaching the ground by an ozone decrease in the stratosphere from a concentration increase in both the troposphere and stratosphere. Wavelength corrections of UV-B (human health (erythema), terrestrial plants (PAS), and phytoplankton (PhAS)) are used to decrease their global levels from latitude band levels combined with geographical distribution in the population and agricultural production. This, in turn, estimates their global level damages corrected by lifetime ODS atmosphere.

\section{Excluded weighting process}

The impact of weighting factor on each endpoint provides an environmental external cost expressed as a single index; we use a conjoint analysis to obtain the weighting factors for the endpoints. Therefore, we can calculate the monetary value of the environmental impact of one unit of each endpoint based on the environmental valuation techniques. Information on this can be found elsewhere (Itsubo et al. 2018; Murakami et al. 2018; Tokimatsu et al. 2016a). As a caveat, we have excluded this weighting process from this study.

\section{Appendix 2. Detailed mathematical formulations in the LIME framework applied on a global scale over time}

\section{Outline}

Table 1 provides a causal chain, DRF, connecting inventory (v), impact category (i), and endpoint (e) in our modeling framework. Appendix 4 provides lists of the meanings of subscripts and abbreviations. The check marks $(\checkmark)$ indicate damage factors (,) corresponding to the inventory, impact categories, and endpoints. The numbers in subscript (e.g., 7 for $\mathrm{m}$ ) represent the number of minerals (i.e., bauxite, coal, copper, iron ore, lead, limestone, and zinc). Since MR contains three endpoints (NR, PP, and BD), the number of damage coefficient (DC) categorized in MR equals 21, provided from LIME.

This appendix provides detailed formulations of DRF and the aggregated form. Details of the development of damage function (DF) and DC in LIME are available in related studies.

$$
\begin{aligned}
& D R_{e, i, j, t}= D F\left(y_{j, t}, T R_{t}, S R_{t}\right)_{e, i} i=G W \\
& D R_{e, i, j, t}=D C_{e, i, j, i} \cdot A_{j, t} \cdot B_{t}\left(\beta\left(T R_{t}\right)\right)_{e=B D} \quad i \neq G W \\
& A_{j, t}= {\left[\left(\frac{P D_{j, t}}{P D_{j, 2000}}\right)_{e=H H} \cdot\left(\frac{y_{j, t}}{y_{j, 2000}}\right)_{e=N R} \cdot\left(\frac{P N_{j, t}}{P N_{j, 2000}}\right)_{e=P P}\right]_{i \neq G W} } \\
& \cdot\left(\frac{O D_{j, t, m=C u, P b, Z n}}{O D_{j, 2000, m=C u, P b, Z n}}\right)_{i=M R}^{-1} \cdot S\left(\alpha_{j}\right)_{e=B D, i=W A}
\end{aligned}
$$

\section{Global warming}

\subsection{Human health $(\mathrm{HH})$}

$\mathrm{DF}$ in $\mathrm{HH}$ [DALY] is formulated by multiple products: the damage per number of deaths (DPD) [DALY/case], the baseline mortality rate (BMR) [case/cap], the population number $\mathrm{N}_{\mathrm{j}, \mathrm{t}}$ [cap], the percentage suffering from the disease, the relative risk $(\mathrm{RR})\left[(\% / \%) /{ }^{\circ} \mathrm{C}\right]$, and the $\mathrm{TR}_{\mathrm{t}}\left[{ }^{\circ} \mathrm{C}\right]$. Both DPD and BMR are expressed as functions of $y_{j, t}$, while $R R$ is tied to $\mathrm{TR}_{\mathrm{t}}$. These DPD, BMR, and $\mathrm{RR}$ are derived from regression analysis based on WHO data after rearranging the original WHO 21 regions for our model (10 regions). The formulation of DF and the regression analysis are based on past studies (Tang et al. 2018a), which were updated based on 2014 estimates from the WHO (Tang et al. 2019). RR, excluding malnutrition, is blended with the 
Fig. 4 Overall structure of LIME
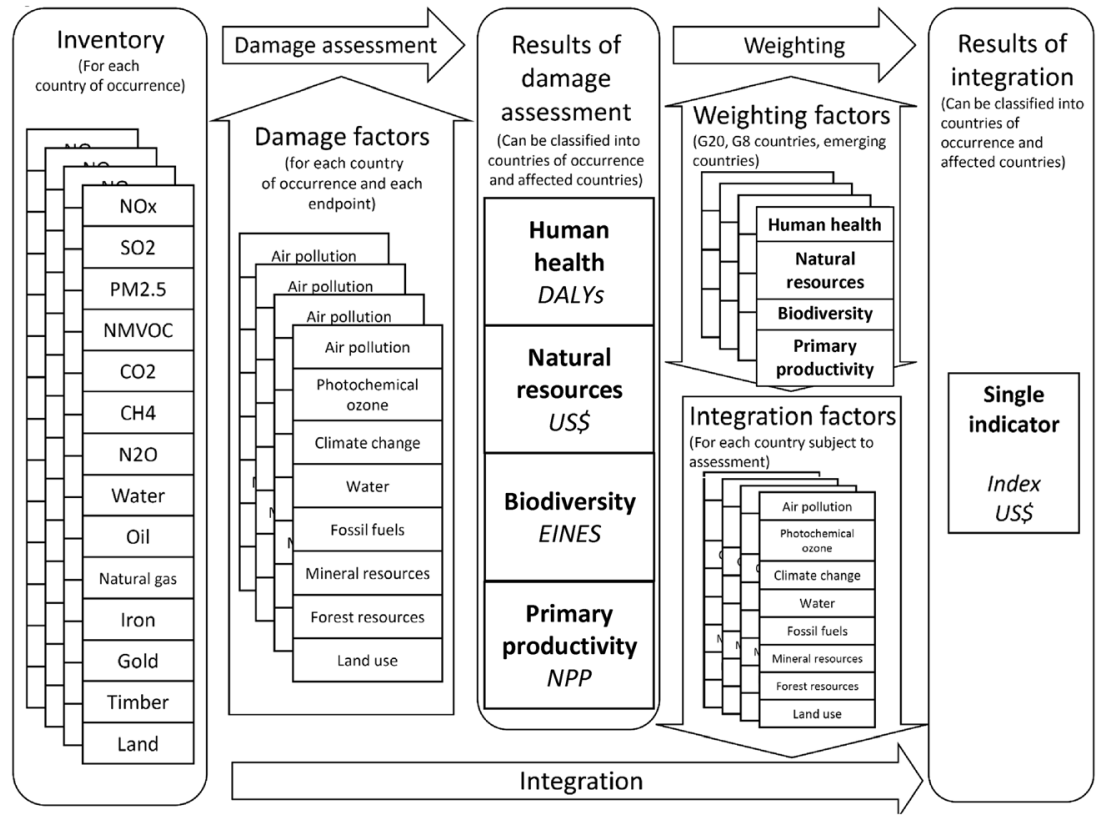

SSP scenario based on scenarios for the years 2030 and 2050 in the WHO (2014) report. RR for malnutrition is formulated as a step function using those scenario levels and BMR in 2030 and 2050. BMR in coastal flooding areas is given a fixed number commonly used in scenarios. DPD is considered the percentage of the population with the target diseases.

$$
\begin{aligned}
& D F_{j, t, i=G W, e=H H}=D P D_{d, j, t}\left(y_{j, t}\right) \\
& \cdot\left[B R_{d, j, t}\left(y_{j, t}\right) \cdot N_{j, t}\right] \\
& \cdot\left[R R_{d, j, t}\left(T R_{t}\right) \cdot T R_{t}\right] \\
& B M R_{d, j, t}=a_{d, j} \cdot \text { power }\left(\mathrm{y}_{\mathrm{j}, \mathrm{t}}, \mathrm{b}_{\mathrm{d}, \mathrm{j}}\right)(d \neq \text { coastal flooding }), \\
& \text { common data setting for } d=\text { coastal flooding }
\end{aligned}
$$

\begin{tabular}{|c|c|}
\hline$B M R_{d, j, t}$ & [case/cap]: Baseline mortality rate in the SSP \\
\hline$D P D_{d, j, t}$ & $\begin{array}{l}{[\mathrm{DALY} / \text { case }] \text { : Health damage per death in the SSP }} \\
\text { scenario, disease, and region at time } t\end{array}$ \\
\hline$N_{j, t}$ & $\begin{array}{l}\text { [cap]: Population number with percentage } \\
\text { suffering from the disease at time } t\end{array}$ \\
\hline$R R_{d, j, t}$ & $\begin{array}{l}{\left[(\% / \%) /{ }^{\circ} \mathrm{C}\right]: \text { Relative risk increase by disease and }} \\
\text { region per } 1{ }^{\circ} \mathrm{C} \text { rise in global average temperature }\end{array}$ \\
\hline$T R_{t}$ & {$\left[{ }^{\circ} \mathrm{C}\right]$ Global mean temperature rise at time $t$} \\
\hline$y_{r, t}$ & [USD/cap]: Per capita GDP at time $t$ \\
\hline & $\begin{array}{l}\text { disease (malaria, diarrhea, malnutrition, } \\
\text { cardiovascular, diseases caused by flooding in } \\
\text { coast and inland) }\end{array}$ \\
\hline
\end{tabular}

where $\begin{array}{ll}j & 10 \text { regions in our model } \\ t & \text { time }(2010,2020, \ldots)\end{array}$

\subsection{Natural resources (NR)}

\subsubsection{Agricultural products}

We express the impacts on agricultural products (i.e., rice, corn, and wheat) by multiplying damage factors with global temperature rise, as follows:

$$
\begin{aligned}
D F_{j, t, i=G W, e=N R, k=f}= & A S P_{f, j, t} \cdot A G P_{f} \cdot\left(T R_{t}-T R_{1990}\right) \\
& \cdot R A P_{f, j}
\end{aligned}
$$

where

$f \quad$ food (rice, corn, and wheat)

$k \quad$ the three sub categories in NR (f,l,r)

$A S P_{f, j, t} \quad$ [USD/Million ton]: shadow prices of the regional agricultural products at time $t$

$A G P_{f} \quad\left[\right.$ Million ton $\left./ \mathrm{yr} /{ }^{\circ} \mathrm{C}\right]:$ parameters for the damages in global level per unit temperature rise

$R A P_{f, j} \quad[\%]$ parameters to allocate the global damages to region $\mathrm{j}$

The $A S P_{f, j, t}$ is derived from marginal changes in land-use cost divided by those in production.

The $A G P_{f}$ is derived from changes in agricultural production between 1990 and when $\mathrm{CO}_{2}$ doubled, divid- 
ed by the global mean temperature rise between the years.

The $R A P_{f, j}$ is derived from the regional products differential between 1990 and when $\mathrm{CO}_{2}$ doubled, divided by the temperature rise.

\subsubsection{Land resources by sea level rise}

The damage to land resources is expressed by submerged area in terms of the unit rise of the sea level, multiplied by the height of the rise in sea level and the areal value, expressed as follows. Unlike the two other categories (i.e., agricultural products and energy), the constant value of the unit price of the land area is applied instead of the shadow value derived from our model.

$D F_{j, t, i=G W, e=N R, k=1}=L A P_{l, j} \cdot S M A_{l} \cdot S R_{t}$

where

$l \quad$ land, tundra, desert, and wetland

$L A P_{l, j} \quad\left[\mathrm{USD} / \mathrm{km}^{2}\right]:$ unit price of land area

$S M A_{l} \quad\left[\mathrm{~km}^{2} / \mathrm{m}\right]$ : submerged land area in a unit rise of sea level, derived from gridded data for coastal lines above $0.5 \mathrm{~m}$, from the sea level; it excludes those with high population density

$S R_{t} \quad[\mathrm{~m}]:$ height of sea level rise at time $t$

\subsubsection{Energy resources}

Impact on energy resources is measured by the economic damage of energy, expressed by the following equation. The first term (SPR) is the shadow price of energy consumed in heating and cooling. The second term is the adjustment by the relative increase in "degree days" (in both heating and cooling) from 1990 multiplied by the third term, per capita energy consumption (RCC) and the population number $(N)$. The fourth term is adjustments for energy consumption, both in ratios of degree days and heat demand per GDP intensity per capita in regions and time, compared with Japan in 1990.

The global mean temperature rise is reflected in the degree day increase multiplied by its unit temperature rise, as in Eq. (11). A simplified regression analysis on energy consumption per capita for cooling and heating with regard to per capita GDP suggested that we apply the two patterns of functions, as in Eqs. (12, $13)$.

$$
\begin{aligned}
& D F_{h, r, j, t, e=N R, k=r}=S P R_{h, r, j, t} \cdot\left(\frac{D D_{h, j . t}\left(T R_{t}\right)-D D_{h, j, 1990}}{D D_{h, j, 1990}}\right) \\
& \cdot\left(R C C\left(y_{j, t}\right)_{h, r, j, t} \cdot N_{j, t}\right) \cdot\left(\left(\frac{D D_{h, j, 1990}}{D D_{h, J P N, 1990}}\right) \cdot\left(\frac{H D C_{j, t} / y_{j, t}}{H D C_{J P N, 1990} / y_{J P N, 1990}}\right)\right)
\end{aligned}
$$

where

$$
\begin{aligned}
& D D_{h, j, t}=D T_{h, j} \cdot\left(T R_{t}-T R_{1990}\right)+D D_{h, j, 1990} \\
& R C C\left(y_{j, t}\right)_{h, r, j, t}=a_{h} \cdot y_{j, t}+b_{h} \quad(\mathrm{~h}=\text { residential heating })
\end{aligned}
$$

$R C C\left(y_{j, t}\right)_{h, r, j, t}=a_{h} \cdot y_{j, t}^{2}+b_{h} \cdot y_{j, t} \quad(\mathrm{~h} \neq$ residential heating $)$

$\mathrm{a}, \mathrm{b}$ : coefficients in the equations

h: residential cooling, business office cooling, residential heating, business office heating

$r \quad$ energy resources (oil for heating, electricity for cooling)

$S P R_{r, j, t} \quad$ [USD/toe]: shadow price of energy resources derived from marginal changes in the energy systems cost divided by those in consumption.

$D D_{h, j, t} \quad\left[{ }^{\circ} \mathrm{C} \cdot\right.$ day $]$ : degree day (for $\mathrm{h}=$ heating with baseline in $14{ }^{\circ} \mathrm{C}$, cooling in $22^{\circ} \mathrm{C}$ )

$D T_{h, j} \quad$ [day]: degree day per unit temperature rise, derived from its rise from $T R_{t}=1.5^{\circ} \mathrm{C}$

$R C C_{h, r, j, t} \quad$ [toe/cap]: energy resource consumption per capita, derived from Japanese historical experiences

$H D C_{j, t} \quad$ [toe/cap]; heat demand per capita endogenously obtained in our energy model

\subsection{Biodiversity}

The damage factors in BD are sourced from Tang et al. (under review), which was revised from lists in LIME3 for the biodiversity impact of global warming $\left(D C_{j, i}=G W, e=\right.$ ${ }_{B D}$ ) $[\mathrm{EINES} / \mathrm{yr}]$ in a grid basis (approximately $10 \mathrm{~km}^{2}$ ), with the regional damage factors aggregated. $D C_{j, i}=G W, e$ $=B D$ is developed from patterns from five global climate models (GCMs), two with/without plant species mobility and three plant taxa (gymnosperms, angiosperms, and pteridophytes with numbers 1052,268000 , and 12000 , respectively).

$D F_{j, t, i=G W, e=B D}=D C_{j, i=G W, e=B D} \cdot T R_{t}$

The factor is estimated from the difference in the reciprocal of time to extinction averaged by the number of 
species divided by temperature difference, then multiplied and summed with the numbers of the three taxa (i.e., 281,052). The differences are between those levels in RCP 8.5 and in RCP 2.6 over 100 years (1970-2070). The time to extinction is determined so that a potential habitat area in 1970 is extinguished (assuming it reaches $1 \mathrm{~km}^{2}$ ) by a speed with ratio between the areas in 2070 and 1970 .

3. Other than global warming: Adjustment for BD by derivations of $\mathrm{B}(\beta)$ and $\mathrm{S}\left(\alpha_{\mathrm{j}}\right)$

The derivation of the damage factor increase $(\mathrm{B}(\beta))$ is as follows. Through a simple regression analysis, we found a good correlation between $\mathrm{E}$ and $\mathrm{V}$ in vascular plants from the Japanese Red Data Book, where

$\log E=a \log V+b$

$E \quad$ indicator to express species extinction, where $E=\sum_{s}\left(1 / T_{a, s}\right.$ $-1 / T_{b, s}$ ), corresponding to the sum of inverse extinction time $(T)$ differential before and after losing one species. $V \quad$ number of endangered vascular plant species

Then $e(\beta)$, the ratio of $E_{2}$ and $E_{1}$ in the current and original state, is expressed using habitat area $R$ and its areal change ratio $\beta$, since $V$ can be considered proportional to $R$.

$$
\begin{aligned}
\frac{E_{2}}{E_{1}} & =\frac{\operatorname{power}\left(10, a \log V_{2}+b\right)}{\operatorname{power}\left(10, a \log V_{1}+b\right)}=\operatorname{power}\left(10, a \log \frac{V_{2}}{V_{1}}\right) \\
& =\left(\frac{V_{2}}{V_{1}}\right)^{a}=\left(\frac{R_{1}-\Delta R_{1}}{R_{1}}\right)^{a}=\left(\frac{1}{1-\beta}\right)^{-a}=e(\beta)
\end{aligned}
$$

where $\beta=\Delta R_{1} / R_{2}, R_{2}=R_{1}-\Delta R_{1}, V_{2}=V_{1}-\Delta V_{1}$

Using the above, $B(\beta)$ can be derived from an integral from 0 to $\beta$, as follows. This function is applicable in $\beta_{j, t}$ (areal changes in forestry plus grassland with time evolution in region $\mathrm{j})$ and $\beta\left(T R_{j, t}\right)$.

$B(\beta)=\int_{0}^{\beta} e(\beta) d \beta=\int_{0}^{\beta}\left(\frac{1}{1-\beta}\right)^{-a} d \beta=\frac{\left(\frac{1}{1-\beta}\right)^{-a-1}-1}{-a-1}$

Next, we defined $\mathrm{S}\left(\alpha_{\mathrm{j}}\right)$ as a magnifying term to adjust between Japan and the target region, regarding the increase in extinction risk of species in which $\alpha$ is defined as the ratio of population density of endangered species in the target country, divided by the Japan values. The function $S\left(\alpha_{j}\right)$ is calibrated using data for Japanese soil and its gravel industry, from which 1.5 and 4.39 are sourced, and $a, b$ are obtained by the regression.

$$
\begin{gathered}
S\left(\alpha_{j}\right)=\frac{\left(1.5 \cdot \alpha_{j}-4.39\right) \cdot a+b}{(1.5-4.39) \cdot a+b} \quad \text { where } \mathrm{a}=6.57 \times 10^{-9}, \\
b=3.74 \times 10^{-8}
\end{gathered}
$$

\section{Appendix 3. The three resource balance models}

\section{Outline}

The three resource balance models use dynamic linear programming at the global level to equate supply and demand for resources. The model includes production, transportation, conversion, final production, disposal, and recycling. The energy model (Tokimatsu et al. 2016c) and the non-fuel mineral resources balance model (Tokimatsu et al. 2017b), the landuse model for biomass and food (Tokimatsu et al. 2017a) calculate the discounted sum of supply costs to determine the structure of demand and supply balance of fuel minerals (i.e., energy) and non-fuel minerals.

The manufacturing sectors of the global economy are proxied using three representative manufacturing sectors: electricity and machinery, construction and building and automobile industry. Non-fuel materials exist as in-use stocks of product goods during the assumed products lifetime, after which they are out-of-use stocks, and finally disposed or recycled.

The land-use model (Tokimatsu et al. 2017a) considers five categories of land use (forestry, grassland, cropland, urban, others) and 20 possible land-use changes between uses. Landuse change is generated through evolutions in demand (food, biomass resources, and urban land use) and supply (land rent, land conversion, biomass and food production) of land.

The three models are integrated (Fig. 5) based on a detailed set of technology options, concerning fuel and non-fuel mineral resources, land use and land-use change. The three resource balance models use dynamic linear programming at the global level to equate supply and demand for resources. The model includes production, transportation, conversion, final production, disposal, and recycling. The left side of Fig. 5 indicates resource supply, while the right side shows the demand side and end-use products and waste disposal. The upper section illustrates mineral and material flows; the lower section shows biomass and food flows, and the middle section shows energy flows.

2. Direct cost formulation from the resource balance models

The supply costs are generated by mining, milling, dressing, smelting, and refining for non-fuel minerals, the conversion process of electrical or chemical energy, and transportation among the ten global regions to final demand. Supply costs TC is divided into energy systems cost EC, non-fuel energy resource cost NFC, and land 
and agriculture related cost LC. Therefore, the total cost

$\mathrm{TC}$ is

$$
\begin{aligned}
= & \sum_{i e} E N C_{i e, g r, r g, y r} \times X E N g r_{i e, g r, r g, y r}+\sum_{i e} T R C C_{r g, y r} \times X I M p r_{i e, r g, y r}+\sum_{r g 1} \operatorname{TRCsSp}_{r g 1, r g} \times X I M c s p_{r g 1, r g, y r} \\
& +\sum_{i p} \sum_{y r 1=y r-n+1}^{y r} P L C e l_{i p, y r 1} \times X N P e l_{i p, y r 1}+\sum_{y r 1=y r-n+1}^{y r} P L C t p_{t p} \times X N P t p_{r g, y r 1}+\sum_{i p} \sum_{y r 1=y r-n+1}^{y r} P L C h 2_{i p} \times X N P h 2_{i p, r g, y r 1} \\
& +\sum_{i p} \sum_{y r 1=y r-n+1}^{y r} P L C c v_{i p} \times X N P c v_{i p, r g, y r 1}+\sum_{i p} E L C_{i p} \times X E L_{i p, r g, y r}+F B C \times X F B R_{r g, y r}+\sum_{i h} \sum_{i d} H T C_{i h, y r} \times X H T_{i h, i d, r g, y r} \\
& +\sum_{i v} \sum_{i t} V 2 C_{i v} \times X B T_{i v, i t, r g, y r}+\sum_{i e} \sum_{i s} D S C_{i e, i s} \times X D M_{i e, i s, r g, y r} \times \sum_{i c} \sum_{r g} D P C_{i c, g r, r g} \times X D P g r_{i c, g r, r g, y r}+\sum_{i c} T R C c o 2_{i c, r g} \\
& \times X D I S P_{i c, r g, y r}
\end{aligned}
$$

and

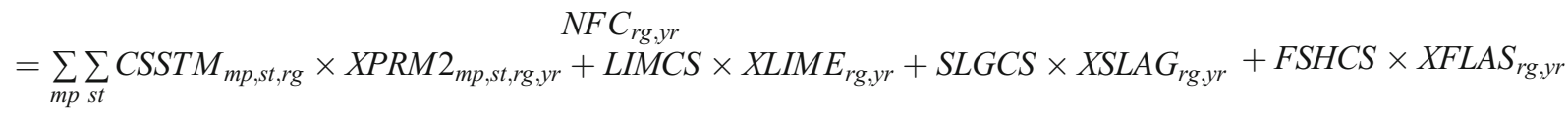

$$
\begin{aligned}
& +M A C C S \times X S G M A_{r g, y r}+\sum_{m t} T_{R} C S M_{m t, r g} \times X I M M_{m t, r g, y r}+\sum_{m p} \sum_{m s} R E F C S M_{m p, r g} \times R F E F M_{m p, m s} \times X M S P_{m p, m s, r g, y r} \\
& +\sum_{i m} \sum_{y r 1=y r-n+1}^{y r} S T L C S_{i m, r g} \times X M P I R_{i m, r g, y r 1}+\sum_{c k} \sum_{y r 1=y r-n+1}^{y r} C K L C S_{c k} \times X M P C K_{c k, r g, y r 1}+\sum_{c m} \sum_{y r 1=y r-n+1}^{y r} C M I C S_{c m} \\
& \times X M P C M_{c m, r g, y r 1}+\sum_{y r 1=y r-n+1}^{y r} C R C S \times X M P C N_{r g, y r 1}+\sum_{m i} \sum_{m d} M P R C S_{m i, m d, r g} \times X M P D_{m i, m d, r g, y r 1} \\
& +\sum_{m c}\left(R E F C S M_{m p=m c, r g}+R E C C S_{m c}\right) \times X R C M_{m c, r g, y r}+\sum_{m s}\left(R E F C S M_{m p=m s, r g}+S E C C S_{m s}\right) \times X S C M_{m s, r g, y r} \\
& +\sum_{m s} \operatorname{STCSIN}_{m c} \times X M S T I N_{m c, r g, y r}+\sum_{m c} \sum_{y r 1=y r-2}^{y r} \operatorname{STCSOT}_{m c} \times X M S T O T_{m c, r g, y r, y r 1}+C R C S \times X C O 2 L_{r g, y r} \\
& +(C R C S+O 2 C S) \times \sum_{y r 1=y r-2}^{y r} X C O 2 C K_{c k, r g, y r, y r 1}+M D P C S \times X_{M D I S P} r g, y r
\end{aligned}
$$

and

$$
\begin{aligned}
& L C_{r g, y r} \\
& =\sum_{l d} L D C_{l d, r g, y r} \times L N D_{l d, r g, y r}+\sum_{l d} \sum_{l d 2} L D C x_{l d, l d 2} \times L N D x_{l d, l d 2, r g, y r}+\sum_{n l} N L D C_{n l} \times N L D_{S T n l, r g, y r}+\sum_{f d} T R C_{F D f d} \times T P N W
\end{aligned}
$$$$
\times F I M_{f d, r g, y r}+\sum_{w d} T R C_{W D, r g, y r} \times W I M_{w d, r g, y r}+\sum_{f d} P R C_{F D f d} \times F P R_{f d, r g, y r}+S P C_{C \operatorname{Prg}} \times F S P_{C \operatorname{Prg}, y r}+\sum_{w d} P R C_{W D w d}
$$$$
\times W P R_{w d, r g, y r}+P R C_{W D w d=W N F} \times X B I O_{i b=W N F, r g k, y r}
$$ 
Table 2 Cost coefficients, decision variables, and subscripts for energy supply model

\begin{tabular}{|c|c|c|c|}
\hline Items & Symbol & Meaning & Unit \\
\hline \multirow[t]{14}{*}{ Cost coefficients } & $X E N g r_{i e, g r, r g}, y r$ & Annual production of fossil and renewable resources by their grade & Gtoe/yr \\
\hline & $X I M p r_{i e, r g, y r}$ & Amount of annual inter-regional transport of the energy resources & Gtoe/yr \\
\hline & $X I M c s p_{r g 1, r g, y r}$ & Amount of annual inter-regional transport of electricity by CSP & $\mathrm{PWh} / \mathrm{yr}$ \\
\hline & $X N P e l_{i p, r g, ~} r r 1$ & Annual construction capacity of the new-build power plants & $\mathrm{TW} / \mathrm{yr}$ \\
\hline & $X N P t p_{i r g}, y r 1$ & Annual construction capacity of the new-build oil refinery & Gtoe/yr \\
\hline & $X N p h 2_{i p, r g, y r 1}$ & Annual construction capacity of the new-build hydrogen production plant & Gtoe/yr \\
\hline & $X N P c v_{i p, r g}, y r 1$ & Annual construction capacity of the new-build other plants & Gtoe/yr \\
\hline & $X E L_{i p, r g, y r}$ & Annual power generation of power plant & $\mathrm{PWh} / \mathrm{yr}$ \\
\hline & $X F B R_{r g}, y r$ & Annual consumption of FBR fuels & Gtoe/yr \\
\hline & $X H T_{i h, i d, r g, y r}$ & Annual consumption of heat utilization & Gtoe/yr \\
\hline & $X B T_{i v, i t, r g, y r}$ & Annual storage power to $\mathrm{V} 2 \mathrm{G}$ & $\mathrm{PWh} / \mathrm{yr}$ \\
\hline & $X D M_{i e, ~ i s, r g, y r}$ & Annual energy consumption & Gtoe/yr \\
\hline & $X D P g r_{i e, g r}, r g, y r$ & Annual amount of storage by their grade & $\mathrm{GtC} / \mathrm{yr}$ \\
\hline & $X D I S P_{i s,} r g, y r$ & Annual amount of storage via $\mathrm{CO} 2$ transport & $\mathrm{GtC} / \mathrm{yr}$ \\
\hline \multirow[t]{8}{*}{ Decision variables } & $X E N g r_{i e,}, g r . r g, y r$ & Annual production of fossil and renewable resources by their grade & Gtoe/yr \\
\hline & $X I M p r_{i e, r g, y r}$ & Amount of annual inter-regional transport of the energy resources & Gtoe/yr \\
\hline & $X I M c s p_{r g 1}, r g, y r$ & Amount of annual inter-regional transport of electricity by CSP & $\mathrm{PWh} / \mathrm{yr}$ \\
\hline & $X N P e l_{i p, r g, y r 1}$ & Annual construction capacity of the new-build power plants & $\mathrm{TW} / \mathrm{yr}$ \\
\hline & $X N P t p_{i r g}, y r 1$ & Annual construction capacity of the new-build oil refinery & Gtoe/yr \\
\hline & $X N P h 2_{i p, r g, y r 1}$ & Annual construction capacity of the new-build hydrogen production plant & Gtoe/yr \\
\hline & $X N P c v_{i p, r g}, y r 1$ & Annual construction capacity of the new-build other plants & Gtoe/yr \\
\hline & $X E L_{i p, r g, y r}$ & Annual power generation of power plant & $\mathrm{PWh} / \mathrm{yr}$ \\
\hline \multirow[t]{11}{*}{ subscripts } & $\mathrm{rg}, \mathrm{rg} 1$ & The 10 regional allocations & \\
\hline & yr, yr1 & The time step & \\
\hline & gr & The grade of the resources & \\
\hline & ie & The primary energy and the secondary energy & \\
\hline & ip & The energy conversion plants & \\
\hline & ih & The heat use technologies & \\
\hline & id & The sectoral heat demand & \\
\hline & iv & The battery types (in transport sector) & \\
\hline & it & The load duration pattern (base, middle, peak) & \\
\hline & is & The final energy demand (power, heat, transport) & \\
\hline & ic & The carbon capture and storage technologies & \\
\hline
\end{tabular}

\section{Appendix 4. List of abbreviations, parameters, subscripts, and variables}

1. Abbreviation

$\begin{array}{ll}\text { AC } & \text { Acidification } \\ \text { AP } & \text { Local air pollution } \\ \text { BD } & \text { Biodiversity }\end{array}$

DALY Disability-adjusted life years

DRF Dose-response function

EINES Expected increase in the number of extinct species

GDP Gross domestic product

GW Global warming

ha Hectare
HH Human health

LIME Lifecycle impact assessment model based on endpoint modeling

LU Land use and land-use change

MR Mineral resources

NOx Nitride oxide

NPP Photosynthetic net primary production

NR Natural resources

OD Ozone depletion

ODS Ozone depletion substances

PP Primary productivity

SSP Shared Socioeconomic Pathways

SOx Sulfide oxide

toe Ton of oil equivalent 
Table 3 Cost coefficients, decision variables, and subscripts for mineral resources supply model

\begin{tabular}{|c|c|c|c|}
\hline Items & Symbol & Meaning & Unit \\
\hline \multirow{19}{*}{$\begin{array}{l}\text { Cost } \\
\text { coefficients }\end{array}$} & $\mathrm{CSSTM}_{\mathrm{mp}, \mathrm{st}, \mathrm{rg}}$ & Excavation, ore dressing, and reaching costs & $\$ / \mathrm{kg}$ \\
\hline & LIMCS & Limestone costs & $\$ / \mathrm{kg}$ \\
\hline & SLGCS & Blast furnace slag costs & $\$ / \mathrm{kg}$ \\
\hline & FSHCS & Fly ash costs & $\$ / \mathrm{kg}$ \\
\hline & MACCS & Crushed rock costs & $\$ / \mathrm{kg}$ \\
\hline & $\mathrm{TRCSM}_{\mathrm{mt}, \mathrm{rg}}$ & Transportation costs & $\$ / \mathrm{kg}$ \\
\hline & $\mathrm{REFCSM}_{\mathrm{mp}, \mathrm{rg}} \times \mathrm{RFEFM}_{\mathrm{mp}, \mathrm{ms}}$ & Smelting, refining, and reaching $(\mathrm{SxEw})$ costs $\times$ losses & $\$ / \mathrm{kg}$ \\
\hline & STLCS $_{\text {irn,rg }}$ & Iron manufacturing costs & $\$ / \mathrm{kg}$ \\
\hline & $\mathrm{CKLCS}_{\mathrm{ck}}$ & Cement kiln facility costs & $\$ / \mathrm{kg}$ \\
\hline & $\mathrm{CMICS}_{\mathrm{cm}}$ & Cement mill facility costs & $\$ / \mathrm{kg}$ \\
\hline & CRCS & Concrete finishing facility costs & $\$ / \mathrm{kg}$ \\
\hline & MPRCS $_{\mathrm{mi}, \mathrm{md}, \mathrm{rg}}$ & Product manufacturing costs & $\$ / \mathrm{kg}$ \\
\hline & $\begin{array}{l}\text { REFCSM }_{\mathrm{mp}=\mathrm{mc}, \mathrm{rg}}+ \\
\text { RECCS }_{\mathrm{mc}}\end{array}$ & Smelting, refining, and reaching (SxEw) costs and scrap collecting and sorting costs & $\$ / \mathrm{kg}$ \\
\hline & $\mathrm{REFCSM}_{\mathrm{mp}=\mathrm{ms}, \mathrm{rg}}+\mathrm{SECCS}_{\mathrm{ms}}$ & Smelting, refining, and reaching (SxEw) costs and process waste collecting and sorting costs & $\$ / \mathrm{kg}$ \\
\hline & $\mathrm{STCSIN}_{\mathrm{mc}}$ & Scrap stock stocking cost & $\$ / \mathrm{kg}$ \\
\hline & $\mathrm{STCSOT}_{\mathrm{mc}}$ & Scrap stock picking cost & $\$ / \mathrm{kg}$ \\
\hline & CRCS & $\mathrm{CO}_{2}$ capture costs for cement kiln facility & $\$ / \mathrm{tC}$ \\
\hline & $\mathrm{O} 2 \mathrm{CS}$ & Oxygen manufacturing facility costs & $\$ / \mathrm{tC}$ \\
\hline & MDPCS & $\mathrm{CO}_{2}$ capture costs & $\$ /$ toe \\
\hline \multirow{19}{*}{$\begin{array}{l}\text { Decision } \\
\text { variables }\end{array}$} & $\mathrm{XPRM} 2_{\mathrm{mp}, \mathrm{st}, \mathrm{rg}, \mathrm{yr}}$ & Mineral ore production amount & Mt \\
\hline & $\mathrm{XLIME}_{\mathrm{rg}, \mathrm{yr}}$ & Limestone supply amount & Mt \\
\hline & $\mathrm{XSLAG}_{\mathrm{rg}, \mathrm{yr}}$ & Blast furnace slag supply amount & Mt \\
\hline & $\mathrm{XFLAS}_{\mathrm{rg}, \mathrm{yr}}$ & Fly ash supply amount & Mt \\
\hline & $\mathrm{XSGMA}_{\mathrm{rg}, \mathrm{yr}}$ & Natural sand, gravel, and crushed rock supply amount & Mt \\
\hline & $\mathrm{XIMM}_{\mathrm{mt}, \mathrm{rg}, \mathrm{yr}}$ & Import amount & Mt \\
\hline & $\mathrm{XMSP}_{\mathrm{mp}, \mathrm{ms}, \mathrm{rg}, \mathrm{yr}}$ & Mineral ore supply amount & Mt \\
\hline & $\mathrm{XMPIR}_{\mathrm{im}, \mathrm{rg}, \mathrm{yr} 1}$ & Iron manufacturing facility capacity & Mt \\
\hline & $\mathrm{XMPCK}_{\mathrm{ck}, \mathrm{rg}, \mathrm{yr} 1}$ & Cement kiln facility capacity & Mt \\
\hline & $\mathrm{XMPCM}_{\mathrm{cm}, \mathrm{rg}, \mathrm{yr} 1}$ & Cement mill facility capacity & Mt \\
\hline & $\mathrm{XMPCN}_{\mathrm{rg}, \mathrm{yr} 1}$ & Concrete finishing facility capacity & Mt \\
\hline & $\mathrm{XMPD}_{\mathrm{mi}, \mathrm{md}, \mathrm{rg}, \mathrm{yr}}$ & Product manufacturing amount & Mt \\
\hline & $\mathrm{XRCM}_{\mathrm{mc}, \mathrm{rg}, \mathrm{yr}}$ & Scrap input amount for refining & Mt \\
\hline & $\mathrm{XSCM}_{\mathrm{ms}, \mathrm{rg}, \mathrm{yr}}$ & Process waste input amount & Mt \\
\hline & XMSTIN $_{\text {me,rg,yr }}$ & Scrap stock stocking amount & Mt \\
\hline & $\mathrm{XMSTOT}_{\mathrm{mc}, \mathrm{rg}, \mathrm{yr}, \mathrm{yr} 1}$ & Scrap stock picking amount & Mt \\
\hline & $\mathrm{XCO}_{2} \mathrm{LM}_{\mathrm{rg}, \mathrm{yr}}$ & $\mathrm{CO}_{2}$ emissions originating in cement kiln lime stones & $\mathrm{GtC}$ \\
\hline & $\mathrm{XCO} 2 \mathrm{CK}_{\mathrm{ck}, \mathrm{rg}, \mathrm{yr}, \mathrm{yr} 1}$ & $\mathrm{CO}_{2}$ emissions originating in fuel for cement kiln & $\mathrm{GtC}$ \\
\hline & $\mathrm{XMDISP}_{\mathrm{rg}, \mathrm{yr}}$ & $\mathrm{CO}_{2}$ emissions originating in fuel for processes other than iron or steel making & $\mathrm{GtC}$ \\
\hline \multirow[t]{13}{*}{ Subscripts } & $r g$ & Region & \\
\hline & $y r, y r 1$ & Point in time & \\
\hline & $m r$ & Mineral ore (copper, lead, zinc, bauxite, iron ore) & \\
\hline & $m p$ & Mineral ore (copper, lead, zinc, alumina, iron ore) & \\
\hline & st & Excavation step & \\
\hline & $m t$ & Mineral ore, base metal and steel, product, scrap & \\
\hline & $m s$ & Base metal and steel (copper, lead, zinc, alumina, steel) & \\
\hline & irn & Iron manufacturing technology & \\
\hline & $c k$ & Cement kiln & \\
\hline & $\mathrm{cm}$ & Cement mill & \\
\hline & $m i$ & Product (copper, lead, zinc, alumina, steel, concrete) & \\
\hline & $m d$ & $\begin{array}{l}\text { Industry (electric machinery, automotive, construction and civil engineering, electric power generation and } \\
\text { communication, etc.) }\end{array}$ & \\
\hline & $m c$ & Scrap (copper, lead, zinc, alumina, automotive steel, electric machinery steel, construction steel, concrete) & \\
\hline
\end{tabular}


Table 4 Cost coefficients, decision variables, and subscripts for land-use model

\begin{tabular}{|c|c|c|c|}
\hline Items & Symbol & Meaning & Unit \\
\hline \multirow[t]{8}{*}{ Cost coefficients } & $L N D_{l d, r g, y r}$ & Cost of land use & $\$ /$ ha \\
\hline & $L D C_{l d, l d 2, r g, y r}$ & Costs of land-use change & $\$ /$ ha \\
\hline & $W L D C_{n l}$ & Penalty cost for land-use in forestry and grass land & Billion \$ \\
\hline & $T R C F D_{f d}$ & Costs of food transportation & $\$ / \mathrm{kg}$ \\
\hline & $T R C W D_{w d, r g, y r}$ & Costs of wood transportation & $\$ / \mathrm{kg}$ \\
\hline & $P R C F D_{f d}$ & $\begin{array}{l}\text { Production costs of foods } \\
\text { (cereals, beef and mutton, chicken and pork) }\end{array}$ & $\$ / \mathrm{kg}$ \\
\hline & $P R C F O_{r g, y r}$ & Production costs of fodder & $\$ / \mathrm{kg}$ \\
\hline & $P R C W D_{w d}$ & Production costs of woods & $\$ / \mathrm{kg}$ \\
\hline \multirow[t]{8}{*}{ Decision variables } & $X L N D_{l d, r g, y r}$ & Area of land use & Gha \\
\hline & $X L D C_{l d, l d 2, r g, y r}$ & Area of land-use change & Gha \\
\hline & $X W L D C_{n l, r g, y r}$ & areas changed in forestry and grass land, percentage of total area & percentage \\
\hline & $X F I M_{f d, r g, y r}$ & Amount of imported food & Mton \\
\hline & $X W I M_{w d, r g, y r}$ & Amount of imported wood & Mton \\
\hline & $X F P R_{f d, r g, y r}$ & Amount of food production & Mton \\
\hline & $X F S P_{r g, y r}$ & Produced amount of fodder & Mton \\
\hline & $X W P R_{w d, r g, y r}$ & Amount of wood production & Mton \\
\hline \multirow[t]{6}{*}{ Subscripts } & $r g$ & $\begin{array}{l}\text { the } 10 \text { regional allocations } \\
\text { the time step }\end{array}$ & \\
\hline & $l d$ & Land use category (before land-use change) & \\
\hline & $l d 2$ & Land use category after land-use change & \\
\hline & $n l$ & Category for land-use change of wilderness & \\
\hline & $f d$ & Cereals, beef \& mutton, chicken \& pork & \\
\hline & $w d$ & logs (for industry, fuel, BECCS), pulp, paper, boards & \\
\hline
\end{tabular}

USD The United States Dollar

WA Waste

WHO World Health Organization

\section{Parameters}

$\mathrm{AGP}_{\mathrm{f}}\left[\right.$ Million ton $\left./ \mathrm{yr} /{ }^{\circ} \mathrm{C}\right] \quad$ parameters for damages at the global level per unit temperature rise in agricultural products

$\mathrm{DC}_{\mathrm{j}, \mathrm{t}}[\mathrm{DALY} /$ ton, USD/ton, damage factors from LIME2 ton/ton, ton/ha, EINES/ton, and LIME3

EINES/ha]

$\mathrm{DT}_{\mathrm{h}, \mathrm{j}}[\mathrm{day}]$

$\mathrm{LAP}_{1, \mathrm{j}}\left[\mathrm{USD} / \mathrm{km}^{2}\right]$

$\mathrm{RAP}_{\mathrm{f}, \mathrm{j}}[\%]$ degree day per unit temperature rise, derived from its rise in $\mathrm{TR}_{\mathrm{t}}=1.5^{\circ} \mathrm{C}$ unit price of land area parameters to allocate the global damages to region $\mathrm{j}$ in agricultural products
$\mathrm{SMA}_{1}\left[\mathrm{~km}^{2} / \mathrm{m}\right]$

$\alpha$

\section{Subscripts}

$\mathrm{a}, \mathrm{b}, \quad$ coefficients used in functions applied by regression c analysis

d disease (malaria, diarrhea, malnutrition, cardiovascular diseases, coastal flooding and inland flooding)

e endpoints (human health (HH), natural resource (NR), primary productivity (PP), and biodiversity (BD))

f foods (rice, corn, and wheat) 
Fig. 5 The three resource models' interlinkages (Represented by moderate resolution)

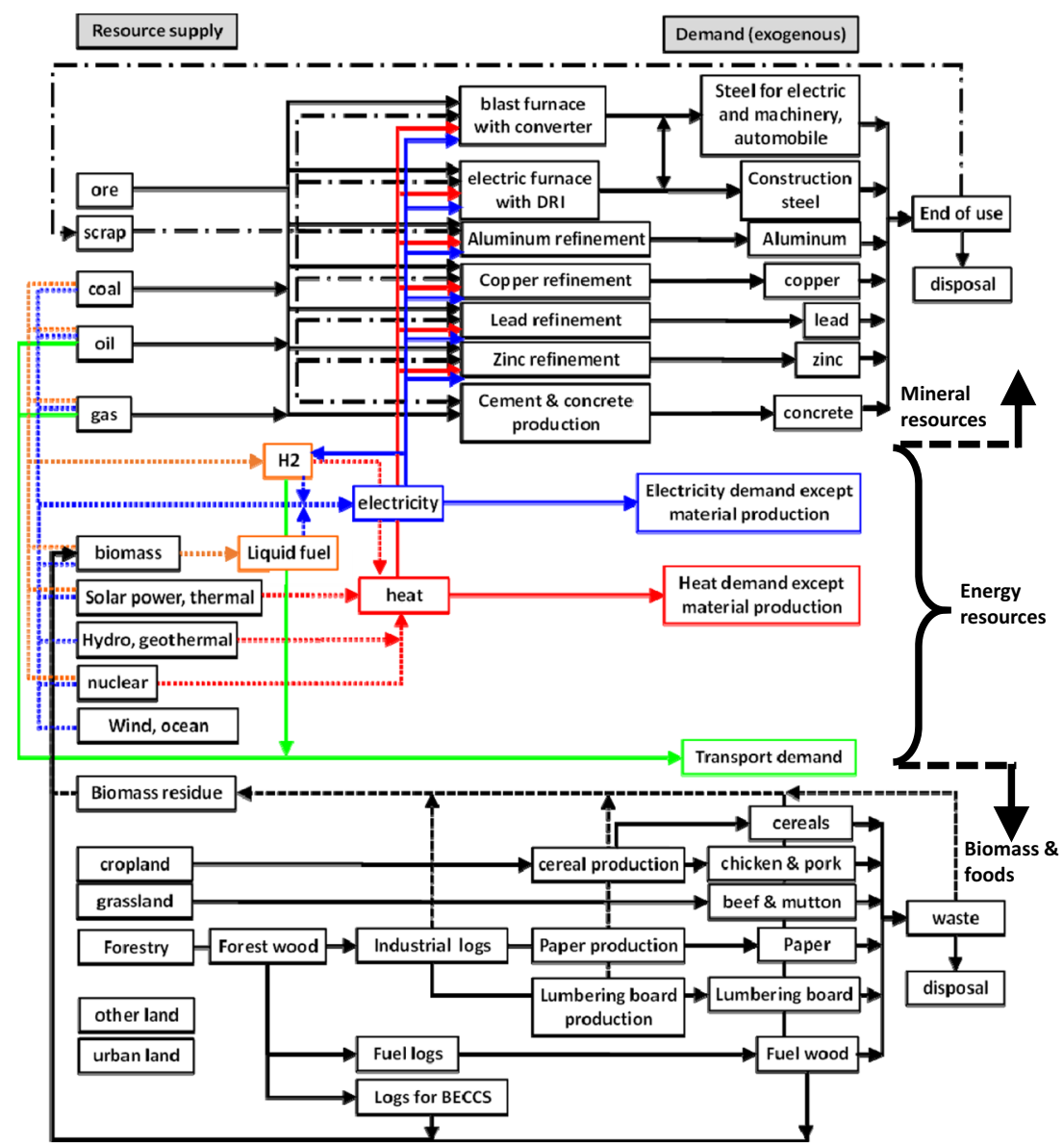

ambient (residential cooling, business office cooling, residential heating, business office heating) impact category (global warming (GW), mineral resources (MR), land use and land-use change (LU), waste (WA), local air pollution (AP), acidification (AC), and ozone depletion (OD))

j 10 regions in our model (North America, West Europe, Japan, Oceania, China, East-South Asia (including Association of Southeast Asian Nations (ASEAN) member countries, plus India), the Middle East and North Africa, Sub-Saharan Africa, Latin America, the former Soviet Union and East Europe) global warming impacts on natural resource $(k=f, 1, r)$ 1 land resources (land, tundra, desert, and wetland)

m minerals (bauxite, coal, copper, iron ore, lead, limestone, zinc) ozone depletion substances (CFC-11, CFC-12, CFC113, CFC-114, CFC-115, CH3CCl3, CCl4, Halon1211, Halon-1301, Halon-2402, HCFC-22, HCFC123, HCFC-141b, HCFC-142b) pollutant ( $\mathrm{SOx}, \mathrm{NOx}$ in sources by point and line) energy resources (oil, electricity) species (vascular plants, unspecified) t 10-year time step $(t=2010,2020, \ldots, 2150)$

$\mathrm{u} \quad$ land use and its change (forestry, grass land, pasture land, human settlement, others)

$\mathrm{v} \quad$ inventories $(\mathrm{v}=\mathrm{m}, \mathrm{o}, \mathrm{p}, \mathrm{u}, \mathrm{w})$

w waste from metals (steel, aluminum, copper, lead, zinc) and concrete
4. Variables

$\mathrm{ASP}_{\mathrm{f}, \mathrm{j}, \mathrm{t}}[\mathrm{USD} / \mathrm{Million}$ shadow prices of the regional ton] agricultural products at time $t$ $\mathrm{B}_{\mathrm{t}}$ $\mathrm{BMR}_{\mathrm{d}, \mathrm{j}, \mathrm{t}}[$ case/cap] damage increase term in biodiversity Baseline mortality rate by scenario, disease, and region at time $\mathrm{t}$

$\mathrm{DD}_{\mathrm{h}, \mathrm{j}, \mathrm{t}}\left[{ }^{\circ} \mathrm{C} \cdot \mathrm{day}\right]$ degree day (for $\mathrm{h}=$ heating with baseline in $14^{\circ} \mathrm{C}$, cooling in $22^{\circ} \mathrm{C}$ )

$\mathrm{DF}_{\mathrm{j}, \mathrm{t}}$ [DALY, USD, dose-response function in global ton, EINES]

$\mathrm{DPD}_{\mathrm{d}, \mathrm{j}, \mathrm{t}}$

[DALY/case]

$\mathrm{DR}_{\mathrm{j}, \mathrm{t}}[\mathrm{DALY}, \mathrm{USD}$, ton, EINES] warming impacts (damage functions) Health damage per death by scenario, disease, and region at time $t$ endpoint damages via dose-response function 


\section{E [EINES]}

$\mathrm{HDC}_{\mathrm{j}, \mathrm{t}}$ [toe/cap]

$\mathrm{N}_{\mathrm{j}, \mathrm{t}}$ [cap]

OD [\%]

$\mathrm{PD}\left[\mathrm{cap} / \mathrm{km}^{2}\right]$

$\mathrm{R}\left[\mathrm{km}^{2}\right]$

$\mathrm{RR}_{\mathrm{d}, \mathrm{j}, \mathrm{t}}\left[(\% / \%) /{ }^{\circ} \mathrm{C}\right]$

$\mathrm{S}$

$\mathrm{SPR}_{\mathrm{r}, \mathrm{j}, \mathrm{t}}[\mathrm{USD} /$ toe $]$

$\mathrm{SR}_{\mathrm{t}}[\mathrm{m}]$

$\mathrm{TR}_{\mathrm{t}}\left[{ }^{\circ} \mathrm{C}\right]$

$\mathrm{V}$

$\mathrm{y}_{\mathrm{j}, \mathrm{t}}[\mathrm{USD} / \mathrm{cap}]$

$\beta$
$\mathrm{PN}$ [ton]

$\mathrm{RCC}_{\mathrm{h}, \mathrm{r}, \mathrm{j}, \mathrm{t}}$ [toe/cap] ratio of species extinction indicator (E) in current and original states

an indicator to express species extinction

heat demand per capita endogenously obtained in our energy model population number at time $\mathrm{t}$ ore degradation $(\mathrm{m}=$ copper, lead, zinc)

population density

habitat areas

energy resource consumption per capita, derived from Japanese historical experiences

$\mathrm{RR}$ increase by disease and by region per $1{ }^{\circ} \mathrm{C}$ rise in global average temperature

a magnifying term to adjust between Japan and the target region for the increase in extinction risk of species shadow price of energy resources derived from marginal changes in the energy systems cost, divided by changes in energy resource consumption

height of sea level rise at time $t$ 10-year time step $(\mathrm{t}=2010,2020, \ldots$, 2150)

global mean temperature rise at time $\mathrm{t}$ number of endangered vascular plant species per capita GDP at time $\mathrm{t}$ ratio of land area change in forestry plus grassland potential NPP

\section{References}

Arvesen A, Luderer G, Pehl M, Bodirsky BL, Hertwich EG (2018) Deriving life cycle assessment coefficients for application in integrated assessment modeling. Environ Model Softw 99:111-125

Bollen et al (2010) An integrated assessment of climate change, air pollution, and energy security policy. Energy Policy 38 . https://doi.org/ 10.1016/j.enpol.2010.03.026

Boubault A, Kang S, Maizi N (2018) Closing the TIMES integrated assessment model (TIAM-FR) raw materials gap with life cycle inventories: integrated assessment using life cycle inventories. J Ind Ecol. https://doi.org/10.1111/jiec. 12780

Connolly D, Lund H, Mathiesen BV, Leahy M (2011) The first step towards a $100 \%$ renewable energy-system for Ireland. Appl Energy 88(2):502-507

De Schryver AM, Brakkee KW, Goedkoop MJ, Huijbregts MAJ (2009) Characterization factors for global warming in life cycle assessment based on damages to humans and ecosystems. Environ Sci Technol 43(6):1689-1695

Fankhauser S (1998) Valuing climate change: the economics of the greenhouse effect. Earthscan, London

Føyn THY, Karlsson K, Balyk O, Grohnheit PE (2011) A global renewable energy system: a modelling exercise in ETSAP/TIAM. Appl Energy 8(2):526-534

García-Gusano D, Istrate IR, Iribarren D (2018a) Life-cycle consequences of internalising socio-environmental externalities of power generation. Sci Total Environ 612:386-391

García-Gusano D, Iribarren D (2018b) Prospective energy security scenarios in Spain: The future role of renewable power generation technologies and climate change implications. Renew Energ 126:202209

García-Gusano D, Iribarren D, Martín-Gamboa M, Dufour J, Espegren K, Lind A (2016) Integration of life-cycle indicators into energy optimisation models: the case study of power generation in Norway. J Clean Prod 112:2693-2696

García-Gusano D, Garraín D, Dufour J (2017a) Prospective life cycle assessment of the Spanish electricity production. Renew Sust Energ Rev 75:21-34

García-Gusano D, Iribarren D, Garraín D (2017b) Prospective analysis of energy security: a practical life-cycle approach focused on renewable power generation and oriented towards policy-makers. Appl Energy 190:891-901

Guinée JB, Cucurachi S, Henriksson PJG, Heijungs R (2018) Digesting the alphabet soup of LCA. Int J Life Cycle Assess 23(7):1507-1511. https://doi.org/10.1007/s11367-018-1478-0

Haberl H, Erb K-H, Krausmann F, Gaube V, Bondeau A, Plutzar C, Gingrich S, Lucht W, Fischer-Kowalski M (2007) Quantifying and mapping the human appropriation of net primary production in earth's terrestrial ecosystems. PNAS 104:12942-12947

Open Access This article is licensed under a Creative Commons Attribution 4.0 International License, which permits use, sharing, adaptation, distribution and reproduction in any medium or format, as long as you give appropriate credit to the original author(s) and the source, provide a link to the Creative Commons licence, and indicate if changes were made. The images or other third party material in this article are included in the article's Creative Commons licence, unless indicated otherwise in a credit line to the material. If material is not included in the article's Creative Commons licence and your intended use is not permitted by statutory regulation or exceeds the permitted use, you will need to obtain permission directly from the copyright holder. To view a copy of this licence, visit http://creativecommons.org/licenses/by/4.0/. JD, Ramirez A, Vega MI, Shi L (2015) Integrated life cycle assessment of electricity-supply scenarios confirms global environmental benefit of lowcarbon technologies. PNAS 112(20):6277-6282

Hong S, Bradshaw CJA, Brook BW (2015) Global zero-carbon energy pathways using viable mixes of nuclear and renewables. Appl Energy 143:451-459

Hordijk L (1995) Integrated assessment models as a basis for air pollution negotiations. Water Air Soil Pollut 85:249-260

Itsubo N, Inaba A (2012) "LIME2 - chapter 2: characterization and damage evaluation methods (2.1 Ozone layer depletion, 2.2 Global warming, 2.3 Acidification)", JLCA Newsletter, JLCA news English edition no. 15, October 2012. http://lca-forum.org/english/ pdf/No15_Chapter2.1-2.3.pdf [accessed October 1, 2019]
Hertwich EG, Gibon T, Bouman EA, Arvesen A, Suh S, Heath GA, Bergesen 
Itsubo N, Inaba A (2013) "LIME2 - chapter 2: characterization and damage evaluation methods (2.4 Urban air pollution)", JLCA Newsletter, JLCA news English edition no. 16, September 2013. http://lca-forum.org/english/pdf/No16_Chapter2.4-2.6.pdf [accessed October 1, 2019]

Itsubo N, Inaba A (2014) "LIME2 - chapter 2: characterization and damage evaluation methods (2.10 Land use, 2.11 Resource consumption, 2.12 Waste)", JLCA Newsletter, JLCA news English edition no. 18, November 2014. http://lca-forum.org/english/pdf/No18 Chapter2.10-2.13.pdf [accessed October 1, 2019]

Itsubo N, Inaba A (2018) LIME3 - environmental impact assessment method enabling LCA in global scale (in Japanese), Maruzen publishing, Tokyo, https://www.maruzen-publishing.co.jp/item/ b302993.html [accessed October 20, 2019]

Itsubo N, Murakami K, Kuriyama K, Yoshida K, Tokimatsu K, Inaba A (2018) Development of weighting factors for G20 countriesexplore the difference in environmental awareness between developed and emerging countries-. Int J Life Cycle Assess 23(12): 2311-2326

Jolliet O, Müller-Wenk R, Bare J, Brent A, Goedkoop M, Heijungs R, Itsubo N, Peña C, Pennington D, Potting J, Rebitzer G, Stewart M, Udo de Haes H, Weidema B (2004) The LCIA midpoint-damage framework of the UNEP/SETAC life cycle initiative. Int J Life Cycle Assess 9(6):394-404

Klaassen G, Riahi K (2007) Internalizing externalities of electricity generation: an analysis with MESSAGE-MACRO. Energy Policy 35: 815-827

Kosugi T, Tokimatsu K, Kurosawa A, Itsubo N, Yagita H, Sakagami M (2009) Internalization of the external costs of global environmental damage in an integrated assessment model. Energy Policy 37(7): 2664-2678

Krajačic G, Duic N, da Graça Carvalho M (2011) How to achieve a 100\% RES electricity supply for Portugal? Appl Energy 88(2):508-517

LCA Society of Japan (2019) https://lca-forum.org/english/lime/ [accessed October 1, 2019]

LC-IMPACT (2019) http://lc-impact.eu/ [accessed October 1, 2019]

Lelieveld J, Evans JS, Fnais M, Giannadaki D, Pozzer A (2015) The contribution of outdoor air pollution sources to premature mortality on a global scale. Nature 525:367-371

Liu W, Lund H, Mathiesen BV, Zhang X (2011) Potential of renewable energy systems in China. Appl Energy 88(2):518-525

Mathiesen BV, Lund H, Karlsson K (2011) 100\% renewable energy systems, climate mitigation and economic growth. Appl Energy 88(2):488-501

MEA (2006) The Millennium Ecosystem Assessment, https://www. millenniumassessment.org/en/index.html [accessed October 1, 2019]

Motoshita M, Ono Y, Pfister S, Boulay AM, Berger M, Nansai K, Tahara $\mathrm{K}$, Itsubo N, Inaba A (2018) Consistent characterisation factors at midpoint and endpoint relevant to agricultural water scarcity arising from freshwater consumption. Int J Life Cycle Assess 23(12):22762287

Murakami K, Itsubo N, Kuriyama K, Yoshida K, Tokimatsu K (2018) Development of weighting factors for G20 countries - part 2: estimation of willingness to pay and annual global damage cost- . Int J Life Cycle Assess 23(12):2349-2364

Østergaard PA, Lund H (2011a) A renewable energy system in Frederikshavn using low temperature geothermal energy for district heating. Appl Energy 88(2):479-487

Østergaard PA, Lund H, Stadler I (2011b) Towards 100\% renewable energy systems. Appl Energy 88(2):419-421

Patrizio P, Leduc S, Chinese D, Kraxner F (2017) Internalizing the external costs of biogas supply chains in the Italian energy sector. Energy 125:85-96

Paulink S, Arvesen A, Stadler K, Hertwich EG (2017) Industrial ecology in integrated assessment models. Nat Clim Chang 7:13-20
Pehl M, Arvesen A, Humpenoder F, Popp A, Hertwich EG, Luderer G (2018) Understanding future emissions from low-carbon power systems by integration of life-cycle assessment and integrated energy modeling. Nat Energy 2:939-945

Pereira HM, et al (2010) Scenarios for global biodiversity in the 21st century. Science 330:1496. https://doi.org/10.1126/science. 1196624

ReCiPe (2018) https://www.rivm.nl/en/Topics/L/Life_Cycle Assessment LCA/ReCiPe [accessed October 1, 2019]

Santoyo-Castelazo E, Azapagic A (2014) Sustainability assessment of energy systems: integrating environmental, economic and social aspects. J Clean Prod 80:119-138

Santoyo-Castelazo E, Stamford L, Azapagic A (2014) Environmental implications of decarbonising electricity supply in large economies: the case of Mexico. Energy Convers Manag 85:272-291

Schenler W, Hirschberg S, Burgherr P, Makowski M, Granat J (2008) "Final report on sustainability assessment of advanced electricity supply options", http://www.needs-project.org/2009/Deliverables/ NEEDS RS2b D10-2\%20-\%20Fina1\%20Report.pdf [accessed October 1,2019$]$

Simpson RD, Toman MA, Ayres RU (2005) "Scarcity and growth revisited: natural resources and the environment in the new millennium". Resources for the Future

Stamford L, Azapagic A (2014) Life cycle sustainability assessment of UK electricity scenarios to 2070. Energy Sustain Dev 23:194-211

Tang L, Ii R, Tokimatsu K, Itsubo N (2018a) Development of human health damage factors related to $\mathrm{CO}_{2}$ emissions by considering future socioeconomic scenarios. Int J Life Cycle Assess 23(12):22882299

Tang L, Nagashima T, Hasegawa K, Ohara T, Sudo K, Itsubo N (2018b) Development of human health damage factors for tropospheric ozone considering transboundary transport on a global scale. Int $\mathrm{J}$ Life Cycle Assess 23(12):2339-2348

Tang L, Higa M, Tanaka N, Itsubo N (2018c) Assessment of global warming impact on biodiversity using the extinction risk index in LCIA: a case study of Japanese plant species. Int J Life Cycle Assess 23(2):314-323

Tang L, Nagashima T, Hasegawa K, Ohara T, Sudo K, Itsubo N (2018d) Development of human health damage factors for PM2.5 based on a global chemical transport model. Int J Life Cycle Assess 23(12): 2300-2310

Tang L, Furushima Y, Honda Y, Itsubo N (2019) Estimating human health damage factors related to $\mathrm{CO} 2$ emissions by considering updated climate-related relative risks. Int J Life Cycle Assess 24(6): $1118-1128$

Tang L, Ohashi H, Hirata A, Matsui T, Tanaka N, Itsubo N (n.d.) "Estimating extinction risk factors related to $\mathrm{CO} 2$ emissions focusing on global plant species". Environ Sci Technol, under review

TEEB (2012) The Economics of Ecosystems and Biodiversity, http:// www.teebweb.org/ [accessed October 1, 2019]

Thomas CD, Cameron A, Green RE, Bakkenes M, Beaumont LJ, Collingham YC, Erasmus BFN, Ferreira de Siqueira M, Grainger A (2004) Extinction risk from climate change. Nature 427(6970): $145-147$

Tokimatsu K, Kaya Y (2004) "Role of innovative technologies for global energy and environment", 19th World Energy Congress, September 5-9, 2004, Sydney, Australia

Tokimatsu K, Kosugi T, Asami T, Williams ED, Kaya Y (2006) Evaluation of lifecycle $\mathrm{CO} 2$ emissions from the Japanese electric power sector in the 21 st century under various nuclear scenarios. Energy Policy 34:833-852

Tokimatsu K, Aicha M, Yoshida K, Nishio M, Endo E, Sakagami M, Murakami K, Itsubo N (2016a) Measuring marginal willingness to pay using conjoint analysis and developing benefit transfer functions in various Asian cities. Int J Sust Dev World 23(6):541-552 
Tokimatsu K, Endo E, Murata A, Okajima K, Nomura N (2016b) An integrated assessment by models for energy systems analysis and life-cycle assessment with a case study of advanced fossil-fired power plants in China. Environ Model Assess 21(2):291-305

Tokimatsu K, Konishi S, Ishihara K, Tezuka T, Yasuoka R, Nishio M (2016c) Global zero emissions scenarios: role of innovative technologies. Appl Energy 162:1483-1493

Tokimatsu K, Yasuoka R, Nishio M (2017a) Global zero emissions scenarios: the role of biomass energy with carbon capture and storage by forested land use. Appl Energy 185(part 2):1899-1906

Tokimatsu K, Murakami S, Adachi T, Ii R, Yasuoka R, Nishio M (2017b) Long-term demand and supply of non-ferrous mineral resources by a mineral balance model. Miner Econ 30(3):193-206

Tokimatsu K, Höök M, McLellan B, Wachtmeister H, Murakami S, Yasuoka R, Nishio M (2018) Energy modeling approach to the global energy-mineral nexus: exploring metal requirement and 2 ${ }^{\circ} \mathrm{C}$ target with $100 \%$ renewable energy scenario. Appl Energy 225:1158-1175

Tokimatsu K, Dupuy L, Hanely N (2019) Using genuine savings for climate policy evaluation with an integrated assessment model. Environ Res Econ 72(1):281-307

Uchijima Z, Seino H (1985) Agroclimatic evaluation of net primary productivity of natural vegetations, 1 : Chikugo model for evaluating net primary productivity. J Agric Meteorol 40:343-352

van Vuuren DP, Riahi K, Moss R, Edmonds J, Thomson A, Nakicenovic N, Kram T, Berkhout F, Swart R, Janetos A, Rose SK, Arnell N (2012) A proposal for a new scenario framework to support research and assessment in different climate research communities. Glob Environ Chang 22(1):21-35

Vanderpaer L, Gibon T (2018) The integration of energy scenarios into LCA: LCM2017 conference workshop, Luxembourg, September 5, 2017. Int J Life Cycle Assess 23(4):970-977
Volkart K (2017) "Long-term technology-based multi-criteria sustainability analysis of energy systems", ETH, Zurich, Switzerland, https://doi.org/10.3929/ethz-b-000183149 [accessed October 1, 2019]

Volkart K, Mutel CL, Panos E (2018) Integrating lifecycle assessment and energy system modelling: methodology and application to the world energy scenarios. Sustainable Production and Consumption 16:121-133

Weidema BP, Schmidt J, Fantke P, Pauliuk S (2018) On the boundary between economy and environment in life cycle assessment. Int $\mathrm{J}$ Life Cycle Assess 23(9):1846-1869

Wigley TML (2010) http://www.cgd.ucar.edu/cas/wigley/magicc/ [accessed October 1, 2019]

Wigley TML, Richels R, Edmonds J (1996) Economics and environmental choices in the stabilization of atmospheric $\mathrm{CO} 2$ concentrations. Nature 379:240-243

World Health Organization (2009) "Global health risks: mortality and burden of disease attributable to selected major risks", http://www. who.int/healthinfo/global_burden_disease/GlobalHealthRisks_ report full.pdf [accessed October 1, 2019]

World Health Organization (2014) "Quantitative risk assessment of the effects of climate change on selected causes of death, 2030s and 2050s", http://apps.who.int/iris/bitstream/handle/10665/134014/ 9789241507691_eng.pdf? sequence $=1 \&$ isAllowed $=y$ [accessed October 1, 2019]

Yamaguchi K, Ii R, Itsubo N (2018) Ecosystem damage assessment of land transformation using species loss. Int $\mathrm{J}$ Life Cycle Assess 23(12):2327-2338

Publisher's note Springer Nature remains neutral with regard to jurisdictional claims in published maps and institutional affiliations. 